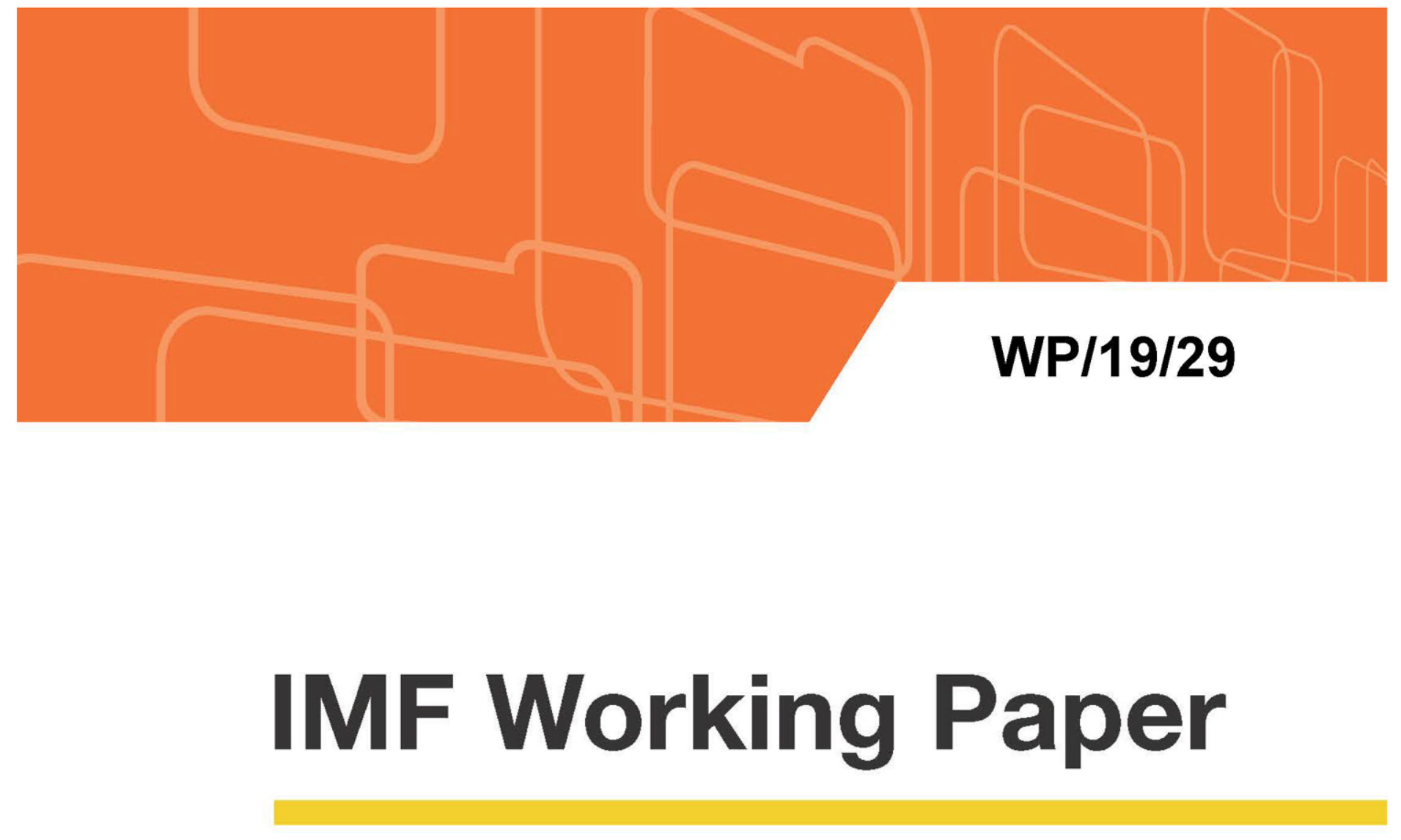

\title{
Do Temporary Business Tax Cuts Matter? A General Equilibrium Analysis
}

by William Gbohoui

IMF Working Papers describe research in progress by the author(s) and are published to elicit comments and to encourage debate. The views expressed in IMF Working Papers are those of the author(s) and do not necessarily represent the views of the IMF, its Executive Board, or IMF management.

$$
\text { I N T E R N A T I O N A L M O N E T A R Y F U N D }
$$




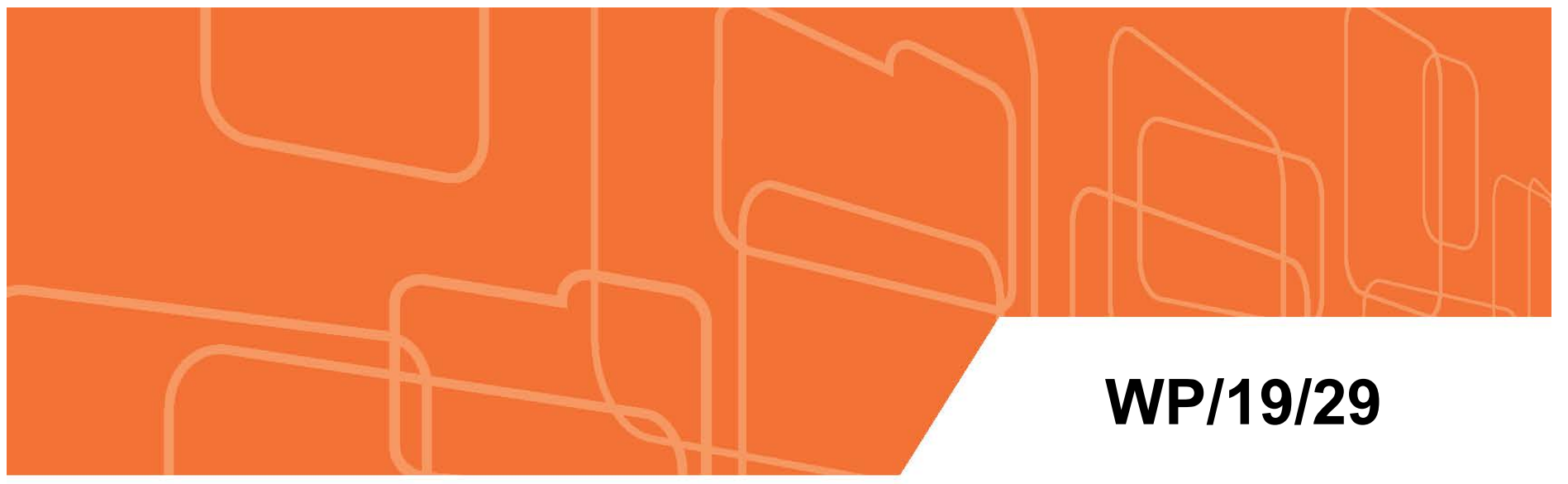

\title{
IMF Working Paper
}

\section{Do Temporary Business Tax Cuts Matter? A General Equilibrium Analysis}

\author{
by William Gbohoui
}

IMF Working Papers describe research in progress by the author(s) and are published to elicit comments and to encourage debate. The views expressed in IMF Working Papers are those of the author(s) and do not necessarily represent the views of the IMF, its Executive Board, or IMF management.

$$
\text { I N T E R N A T | O N A L M O N E T A R Y F U N D }
$$




\title{
IMF Working Paper
}

Fiscal Affairs Department

\section{Do Temporary Business Tax Cuts Matter? A General Equilibrium Analysis ${ }^{1}$ Prepared by William Gbohoui}

Authorized for distribution by Catherine Pattillo

February 2019

\section{IMF Working Papers describe research in progress by the author(s) and are published to elicit comments and to encourage debate. The views expressed in IMF Working Papers are those of the author(s) and do not necessarily represent the views of the IMF, its Executive Board, or IMF management.}

\begin{abstract}
This paper develops a dynamic general equilibrium model to assess the effects of temporary business tax cuts. First, the analysis extends the Ricardian equivalence result to an environment with production and establishes that a temporary tax cut financed by a future tax-increase has no real effect if the tax is lump-sum and capital markets are perfect. Second, it shows that in the presence of financing frictions which raise the cost of investment, the policy temporarily relaxes the financing constraint thereby reducing the marginal cost of investment. This direct effect implies positive marginal propensities to invest out of tax cuts. Third, when the tax is distortionary, the expectation of high future tax rates reduces the expected marginal return on investment mitigating the direct stimulative effects.
\end{abstract}

JEL Classification Numbers: D92, E22, E62, G35, H32

Keywords: Ricardian Equivalence, Corporate Tax Policy, Financing Friction, General Equilibrium.

Author's E-Mail Address: WGbohoui@,imf.org

\footnotetext{
${ }^{1}$ A previous version of this paper is a chapter in the thesis of William Gbohoui and has been presented at various conferences. For useful comments, I wish to thank Julien Bengui, Emanuela Cardia, Rui Castro, Baris Kaymak, Catherine Pattillo, Markus Poschke, Francisco Ruge-Murcia; and seminar attendants at the Fiscal Affairs Department-IMF, the Université de Montréal, Concordia University, and the 2014 Canadian Economic Association Conference. The usual disclaimer applies.
} 


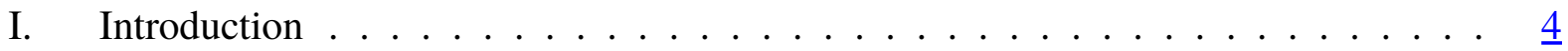

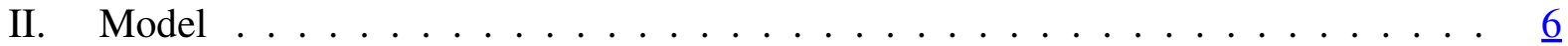

A. Firm ...................... $\underline{6}$

B. Household ....................... . . $\underline{8}$

C. Government ........................... 2

D. Competitive Equilibrium . . . . . . . . . . . . . . . . . 10

E. Ricardian Equivalence with Corporate Taxation . . . . . . . . . . . . . . 10

III. Departure from the Ricardian Result . . . . . . . . . . . . . . . . . . . . 11

A. Financing Frictions . . . . . . . . . . . . . . . 12

B. Financial Frictions and Corporate Taxation . . . . . . . . . . . . 12

C. Firm's Financial Policy . . . . . . . . . . . . . . . . 14

D. Firm's Investment Policy . . . . . . . . . . . . . . . . . . . . . . . . . . . . . . .

E. Other Agents' Problems . . . . . . . . . . . . . . . . . . . 17

IV. Model Solution . . . . . . . . . . . . . . . . . . . . . 17

A. Steady State Properties . . . . . . . . . . . . . . . . . . . . . . . . . . . . . .

B. Parameterization and Numerical Algorithm . . . . . . . . . . . . . 19

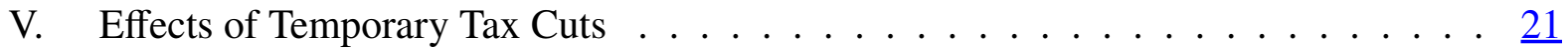

A. Policy Experiments . . . . . . . . . . . . . . . . . 21

B. Transitional Dynamics After Tax Cuts . . . . . . . . . . . $\underline{23}$

C. Sensitivity analysis . . . . . . . . . . . . . . . . . 27

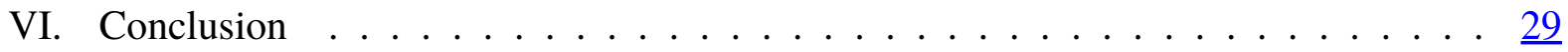

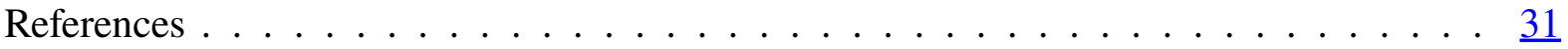

Appendices

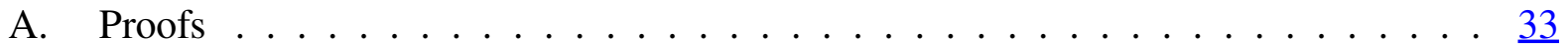

A.1. Ricardian equivalence result with Corporate Taxation . . . . . . . . $\underline{33}$

A.2. Proof of lemma $1 \ldots \ldots \ldots \ldots \ldots$

A.3. Proof of proposition $4 \ldots \ldots \ldots \ldots \ldots$

A.4. Proof of Proposition $5 \ldots \ldots \ldots \ldots \ldots$

A.5. Proof of Proposition $6 \ldots \ldots \ldots \ldots \ldots$

A.6. Proof of Lemma $2 \ldots \ldots \ldots$

A.7. Proof of Proposition $7 \ldots \ldots \ldots \ldots \ldots$

A.8. Proof of Proposition $8 \ldots \ldots \ldots \ldots \ldots \ldots$

A.9. Proof of lemma $3 \ldots \ldots \ldots \ldots$. . . . . . . . . . . . . . . . . . . . .

B. Numerical Algorithm . . . . . . . . . . . . . . . 


\section{Tables}

1. Baseline Parameterization . . . . . . . . . . . . . . . . 20

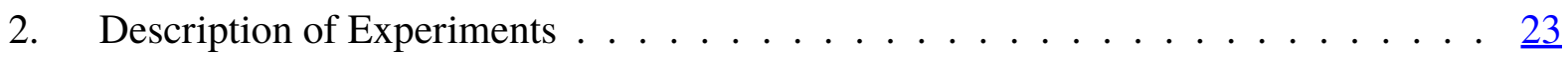

Figures

1. Laffer Curve . . . . . . . . . . . . . . . . . . . . . . 21

2. Illustration of Tax Policy Experiment (lump-sum tax) . . . . . . . . . . 22

3. Transitional Dynamics without Financing Frictions . . . . . . . . . $\underline{\underline{25}}$

4. Transitional Dynamics with Financing Frictions . . . . . . . . . . . $\underline{26}$

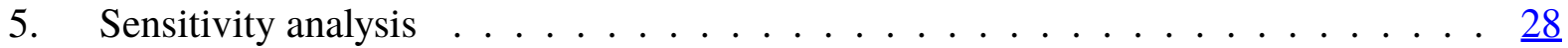




\section{INTRODUCTION}

This paper aims at answering a question of significant interest for both economists and policymakers: Do temporary tax reliefs to business affect the economy? Policymakers often rely on temporary corporate tax cuts to stimulate or to stabilize the economy (e.g. Bush, Obama and Trump tax cuts in the U.S., Harper and Trudeau tax cuts in Canada). In the macroeconomic literature, the Ricardian equivalence theorem, revisited by Barro (1974), predicts an equivalence in terms of prices and allocations between any two time paths of lump-sum taxes that imply the same total present value for tax revenue if individuals live infinitely, are rational and farsighted, and the capital market is perfect. This theory has been extensively analyzed on the consumer side and related theoretical and empirical studies concentrated on personal income taxes. Despite the faith of policymakers in temporary tax incentives to influence firms' decisions, there have been relatively few attempts to assess the validity of the Ricardian result on the firm side.

Against this background, our analysis draws on the macroeconomic literature that analyzes the effects of temporary corporate tax cuts. Abel (1982); Auerbach and Hines (1987); Auerbach and Kotlikoff (1987) study the effects of corporate tax changes, but they do not provide a general equilibrium analysis. In a general equilibrium model, Gourio and Miao (2011) quantify the effects of the 2003 dividend and capital gain tax cuts in U.S. assuming that they are temporary. However, their analysis does not isolate the incentive effects from the timing effects of tax cuts. Using stochastic tax rates, Dotsey (1994) shows that lowering taxes on capital and financing government spending by higher deficit reduces investment. In contrast, we consider deterministic tax rates in line with Heathcote (2005) ${ }^{1}$, but focus on business taxes. Building on the literature which studies the macroeconomic effects of financial frictions, (Bianchi, 2016; Gomes, 2001; Greenwald, Stiglitz, and Weiss, 1984; Myers and Majluf, 1984), we also introduce a constraint on external financing to assess how capital market imperfections interact with tax policies in distorting firms' investment decisions.

We focus on a simple general equilibrium model which integrates a representative household, a government and a representative firm. The government finances a time-invariant spending out of business taxes using one period bonds. The household derives utility from consumption, holds shares in firms and trades government debt. The firm owns capital and is potentially subject to a minimum dividend distribution policy. Accordingly, its optimal investment may require some external funding in addition to internal cash flows. But, we consider that equity issuance is costly. In this framework, we assume that the economy starts initially from a steady-state

\footnotetext{
${ }^{1}$ The literature on Ricardian equivalence is summarized by Seater (1993) and Ricciuti (2003)
} 
with zero government debt. Then, the government unexpectedly reduces business taxes for one period and issues bonds to finance its spending. One period later, it increases corporate taxes by an amount sufficient to cover not only its current spending, but also the full servicing of the outstanding debt. Thereafter, the government re-sets the tax rate to its initial steady-state value, with zero public debt issuance. After the initial tax cut, agents in our model have full information about the new government policy, and perfect foresight about its future effect on prices. Following the tax increase, the economy goes into a transition, which we compute, but converges back to the initial steady-state.

The novelty of the paper is at least twofold. The empirical evidence indicates that tax cuts do not pay for themselves causing deficits paid, at least partially, by future tax increases (Bohn, 1990; Mankiw and Weinzierl, 2006), suggesting that that future tax policies must be taken into account when assessing the effects of current tax policy. In this respect, our policy experiment offers a more appropriate laboratory to assess the validity of Ricardian equivalence. The existing literature either assumes that any reduction in government revenue due to temporary tax cuts is instantaneously absorbed by a reduction in lump-sum transfers, missing the potential liquidity effects of government bonds, or allows government debt to increase permanently following temporary tax cuts, making it difficult to differentiate the effects of larger government size from those of the tax cuts. In addition, considering both lump-sum and proportional taxes in the same framework permits isolating the stimulative effects of tax cuts from the inter-temporal substitution effects largely studied in the literature. To allow this comparability of the results under different tax instruments, the calibration of the model is simplified accordingly and does not intend to necessarily match firms dynamics in the data.

We begin by extending the Ricardian equivalence result to the firm side. We find that in the absence of financing frictions, consistently with the well-known Modigliani and Miller (1958) theorem, the capital structure of the firm is irrelevant for its investment decision. Especially, we establish that temporary reductions in corporate profit taxes have no real effects if the tax is lump-sum, the present value of tax burden is unchanged, and capital markets are perfect. When the lump-sum tax is lowered, the firm uses the extra cash-flows to pay more dividends or to repurchase equity. Stockholders save the extra revenue by investing in government debt. When government increases taxes later, the firm reduces dividend payments or issues new equity to finance the higher tax, leaving its investment plan unaffected. The household keeps its consumption plan unchanged and uses its savings plus interest to buy equity issued by the firm, or to compensate the reduction in revenue due to lower dividend payments. As a result, all adjustment takes place through changes in the capital structure of the firm and implies 
no real effects. But, the expectations of higher future tax rates reduce the expected marginal return on investment implying lower current investment if the tax is proportional to profits.

In the presence of financing frictions, the firm uses external financing if and only if the dividend constraint is binding. The results highlight that the investment response varies both quantitatively and qualitatively, depending on whether the tax is lump-sum or not, as well as on the marginal cost of external financing. More precisely, two opposite forces are present. On one hand, the tax cut reduces the marginal cost of investment because it allows the firm to use retained-earnings as a source of investment financing, avoiding the additional cost associated with equity issuance. When the tax is lump-sum, these direct stimulative benefits imply an increase in investment. On the other hand, the expectation of high future tax rates reduces the expected marginal return on investment and mitigates the direct benefits of the tax cut when tax is proportional to business profit. The net effect depends on the amount of financial frictions in place before the tax cut, and the size of the tax stimulus.

The remainder of the paper is organized as follows. Section II presents the basic framework and establishes a Ricardian equivalence result with corporate tax. Section III discusses how strong the Ricardian forces are in the presence of financing frictions and distortionary taxation. Section IV derives the solution of the model. Section V presents the dynamics of the economy following tax cuts. Section VI is devoted to concluding remarks.

\section{ModeL}

Time is discrete and runs from $t=0$ to $\infty$. The economy consists of a representative household, a representative firm, and a government.

\section{A. Firm}

A representative firm combines labor $N_{t}$ and capital $K_{t}$ to produce a final good using Cobb-Douglas production technology with a Constant Return to Scale (CRS), $Y_{t}=K_{t}^{\alpha}, N_{t}^{1-\alpha}$. Physical capital depreciates geometrically at rate $\delta$ leading to the following law motion of capital:

$$
K_{t+1}=I_{t}+(1-\delta) K_{t}
$$

where $I_{t}$ is the investment at period $\mathrm{t}$ and $K_{t}$ the capital stock at the beginning of period t. 
The firm may issue new shares or repurchase old shares. Thus, the price of the firm at date $t+$ 1 satisfies: $P_{t+1}=P_{t+1}^{0}+Z_{t+1}$, where $Z_{t+1}$ denotes the value of new shares issued (repurchased) at period $t+1$ if $Z_{t+1} \geq(<) 0$, and $P_{t+1}^{0}$ is the period $t+1$ value of equity outstanding in period $t$. The managers of the firm act on behalf of the stockholders in order to maximize the value of the firm. The net after-tax return to the owners of the firm at time t comprises current dividends and capital gains. Under the assumption of no uncertainty and perfect capital markets, the return on firms' shares must equal the return on government bonds, $r_{t+1}$, if the owners are to be content holding their shares in equilibrium. Let's denote by $D_{t+1}$ the dividend payments of the firm at period $t+1$,

$$
r_{t+1}=\frac{\left(P_{t+1}^{0}-P_{t}\right)+D_{t+1}}{P_{t}}
$$

where the term in parentheses represents the capital gains component of the return. The equity value of the firm stems from the non-arbitrage condition governing the valuation of its shares and can be derived as:

$$
P_{t}=\frac{\left(P_{t+1}-Z_{t+1}\right)+D_{t+1}}{1+r_{t+1}}
$$

I follow Gourio and Miao (2010) and define the cum- dividend equity value, $V_{t+1}$, at period $t+1$ as:

$$
V_{t+1}=P_{t+1}-Z_{t+1}+D_{t+1}
$$

Using (2):

$$
V_{t}=P_{t}-Z_{t}+D_{t}=D_{t}-Z_{t}+\frac{V_{t+1}}{1+r_{t+1}}
$$

In the absence of any bubbles, solving (4) forward and using the transversality condition on stock prices, $\lim _{T \rightarrow \infty} \prod_{t=0}^{T}\left(1+r_{t}\right)^{-1} P_{T+1}=0$, yields the firm's market value at period 0 given by:

$$
V_{0}=\sum_{t=0}^{+\infty} \prod_{i=0}^{t-1} \frac{1}{1+r_{i+1}}\left(D_{t}-Z_{t}\right)
$$

Here $\Lambda_{0, t}=\prod_{i=0}^{t-1} \Lambda_{i, i+1}=\prod_{i=0}^{t-1} \frac{1}{1+r_{i+1}}$ is the firm's discount factor between periods 0 and $\mathrm{t}$. The value of the firm is simply the present discounted value of its future dividend stream. This specification implies that dividends are paid out at the end of the period. The firm takes employment, investment and financing decisions to maximize its market value (5) subject to the law motion of capital (1), and its resource constraint:

$$
D_{t}=F\left(K_{t}, N_{t}\right)+Z_{t}-w_{t} N_{t}-I_{t}-\tau_{t}
$$


where $\tau$ is a lump-sum tax on corporate profits. Dividends are defined as the the firm's residual profits after expenditures. Cash inflows include current output and undepreciated capital, while cash outflows consist of dividend and factor payments, tax liability and investment expenditures. Under the assumption of perfect capital markets, the capital structure does not matter for the firm's value. In other words, it does not matter for the firm's value and investment policy how much earnings to retain for use as internal financing, rather than distributing dividends and raising new equity in the external equity market. More precisely in the firm's problem, the payout $D_{t}-Z_{t}$ can be determined but $D_{t}$ and $Z_{t}$ will be undetermined. This is the Modigliani and Miller (1958) dividend policy irrelevance theorem. Thus, for the remainder of this section, I define for simplicity the payouts of the firm as $d_{t}$ :

$$
d_{t}=D_{t}-Z_{t}
$$

Substituting sequentially (7) into (6) and (5) for $d_{t}$, and using (1) to eliminate $I_{t}$ from the problem, the first-order conditions of the firm's maximization problem are:

$$
\begin{aligned}
w_{t} & =F_{2}\left(K_{t}, N_{t}\right) \\
r_{t+1} & =F_{1}\left(K_{t+1}, N_{t+1}\right)-\delta
\end{aligned}
$$

Equation (8a) implies that wage equals the marginal product of labor. The left-hand side of equation (8b) shows the marginal cost of investing one unit of output in physical capital. Equation (8b) implies that the return on investment in physical capital equals the return on investment in government bonds.

\section{B. Household}

The representative household derives utility from consumption alone, according to a standard time-additive utility function $U(C)=\log C$, with future utility discounted at rate $0<\beta<1$. A time endowment of 1 is supplied inelastically every period.

The household trades equity shares in the firm, as well as a government bond. Let $\theta_{t}$ denote the shareholding at the start of period $t$ valued at price $P_{t}^{0}, P_{t}$ the equity price at the end of period $\mathrm{t}$ (including capital gain in $t$ ), and $B_{t+1}$ the government bondholding paying interest rate $r_{t}$. 
The problem of the representative household can be derived as follows:

$$
\max _{C_{t}, B_{t+1}, \theta_{t+1}} \sum_{t=0}^{+\infty} \beta^{t} U\left(C_{t}\right)
$$

subject to

$$
\begin{aligned}
B_{t+1}+C_{t}+\theta_{t+1} P_{t} & =w_{t}+\theta_{t}\left(P_{t}^{0}+D_{t}\right)+\left(1+r_{t}\right) B_{t} \\
\lim _{T \rightarrow \infty} \prod_{t=0}^{T}\left(1+r_{t}\right)^{-1} B_{T+1} & \geq 0 \\
\lim _{T \rightarrow \infty} \prod_{t=0}^{T}\left(1+r_{t}\right)^{-1} \theta_{T+1} & \geq 0
\end{aligned}
$$

Equation (10a) is the household's budget constraint. The household's income consists of labor earnings, plus the income from government bondholding, plus shareholding income. The consumer spends his resources in consumption, government bonds, and equity purchases.

Equations (10b) and (10c) represent the no-Ponzi game constraints on government bonds and firm's shares holdings, respectively.

\section{First-Order Conditions}

$$
\begin{aligned}
U^{\prime}\left(C_{t}\right) & =\beta\left(1+r_{t}\right) U^{\prime}\left(C_{t+1}\right) \\
P_{t} U^{\prime}\left(C_{t}\right) & =\beta U^{\prime}\left(C_{t+1}\right)\left(P_{t+1}^{0}+D_{t+1}\right)
\end{aligned}
$$

Equation (11b) implies that the stock price $P_{t}$ is given by the discounted present value of dividends. In addition, equations (11a-11b) imply that the gross return on government bonds

equals the inter-temporal marginal rate of substitution of consumption, which equals the return on the firm's shares.

\section{Government}

Government spends a constant amount of resources $G>0$ at each time $t$, funded either by lump sum corporate taxation $\tau_{t}$, or by issuing one period debt $B_{t+1}$ held by the representative consumer. The government's budget constraint is

$$
\left(1+r_{t}\right) B_{t}+G=\tau_{t}+B_{t+1}
$$


together with the no Ponzi game condition:

$$
\lim _{T \rightarrow \infty} \prod_{t=0}^{T}\left(1+r_{t}\right)^{-1} B_{T+1} \leq 0
$$

Requiring that the government wastes no resources and therefore satisfies the no Ponzi game condition with equality, I obtain the present value budget constraint:

$$
B_{0}+G \sum_{t=0}^{\infty} \prod_{i=0}^{t}\left(1+r_{i}\right)^{-1}=\sum_{t=0}^{\infty} \prod_{i=0}^{t}\left(1+r_{i}\right)^{-1} \tau_{t},
$$

where I assume $B_{0}=0$. The government's policy will be a sequence $\left\{\tau_{t}, B_{t+1}\right\}_{t=0}^{\infty}$ of tax rates and debt issuance which satisfies (13).

\section{Competitive Equilibrium}

Given the government policy $\left\{\tau_{t}, B_{t+1}\right\}_{t=0}^{+\infty}$, a competitive equilibrium consists of a set of prices $\left\{w_{t}, r_{t}, P_{t}\right\}_{t=0}^{+\infty}$, and allocations $\left\{C_{t}, N_{t}, K_{t+1}, B_{t+1}, d_{t}, \theta_{t+1}\right\}_{t=0}^{+\infty}$, such that: the household optimizes given prices, the firm optimizes given prices and the tax rate, the government satisfies its inter-temporal budget constraint and all markets (good, firm's shares, bond and labor) clear.

\section{E. Ricardian Equivalence with Corporate Taxation}

\section{Proposition 1. Ricardian Equivalence Statement}

Given initial conditions $\left(B_{0}, K_{0}\right)$, and a government spending $G^{2}$, let the set of allocations $\left\{C_{t}, N_{t}, K_{t+1}, B_{t+1}, \theta_{t}, d_{t}\right\}_{t=0}^{+\infty}$ and prices $\left\{w_{t}, r_{t}, P_{t}\right\}_{t=0}^{+\infty}$, be an initial equilibrium under a government policy $\left\{\tau_{t}, B_{t+1}\right\}_{t=0}^{+\infty}$.

If $\left\{\hat{C}_{t}, \hat{N}_{t}, \hat{K}_{t+1}, \hat{B}_{t+1}, \hat{\theta}_{t}, \hat{d}_{t}\right\}_{t=0}^{+\infty}$ and $\left\{\hat{w}_{t}, \hat{r}_{t}, \hat{P}_{t}\right\}_{t=0}^{+\infty}$ constitute another equilibrium with a government policy $\left\{\hat{\tau}_{t}, \hat{B}_{t+1}\right\}_{t=0}^{+\infty}$, such that:

\footnotetext{
${ }^{2}$ While we have assumed constant government spending in the previous sections, the result does not require such assumption to be valid.
} 


$$
\begin{aligned}
& \sum_{t=0}^{+\infty} \prod_{i=0}^{t}\left(1+\hat{r}_{i}\right)^{-1} \hat{\tau}_{t}=\sum_{t=0}^{+\infty} \prod_{i=0}^{t}\left(1+r_{i}\right)^{-1} \tau_{t} . \text { Then: } \\
&\left\{\hat{C}_{t}, \hat{N}_{t}, \hat{K}_{t+1}, \hat{\theta}_{t}\right\}_{t=0}^{+\infty}=\left\{C_{t}, N_{t}, K_{t+1}, \theta_{t}\right\}_{t=0}^{+\infty} \\
&\left\{\hat{w}_{t}, \hat{r}_{t}, \hat{P}_{t}\right\}_{t=0}^{+\infty}=\left\{w_{t}, r_{t}, P_{t}\right\}_{t=0}^{+\infty} \\
& \hat{d}_{t}+\hat{\tau}_{t}=F\left(K_{t}, N_{t}\right)+(1-\delta) K_{t}-w_{t} N_{t}-K_{t+1} \\
& \hat{B}_{t+1}-R_{t} \hat{B}_{t}-\hat{d}_{t}=w_{t} N_{t}-C_{t} \\
& \hat{B}_{t+1}+\hat{\tau}_{t}-R_{t} \hat{B}_{t}=G
\end{aligned}
$$

According to the theorem, the temporal pattern of lump-sum tax required to finance a particular public expenditure stream is irrelevant to the determination of real variables of the economy. That is, substituting taxes today for taxes plus interest tomorrow via debt financing affects neither the investment decision of the firm, nor the wealth of the individuals. The reason is that under perfect capital markets, infinitely lived and perfect foresighted private agents can exactly undo any financing policy undertaken by the government ${ }^{3}$. Given the Barro (1974)'s Ricardian equivalence result, the statement established here is not surprising but it has some implications which are absent in the standard Ricardian equivalence analysis. For instance, it helps characterizing the effects of the policy on the optimal decisions of the firm and their transmission channel to other variables in the economy. In addition, it is useful for understanding the dynamics of the economy when we depart from the Ricardian framework.

\section{Departure from the Ricardian Result}

As in the standard Ricardian equivalence theorem, the result established in proposition 1 will fail if one or more of the assumptions behind the result are violated. This paper focuses on two important deviations from the basic framework. First, we impose a lower bound on dividend payment and introduce costly external financing. Afterwards, we consider proportional rather than lump-sum corporate taxation.

\footnotetext{
${ }^{3} \mathrm{~A}$ detailed analytical proof is given in annex A.1.
} 


\section{A. Financing Frictions}

The analysis of the effects of temporary tax cuts on firm decisions requires a model that departs from Modigliani-Miller. To achieve this, we impose two standard constraints on firm financing decisions.

First, we impose a lower bound on dividend payments. A possible interpretation is that the firm has an established dividend practice that leads stockholders to expect a minimum dividend payment, $\hat{D}$, after each operating year. Such a restriction can be justified by appealing to the notion that minimum dividend payments may help reduce agency problems between shareholders and managers and work as a signaling device (see Allen and Michaely (2003) for a review). Bianchi (2016) also adopts a similar dividend payout policy. Poterba, Hall, and Hubbard (1987) presented evidence of the remarkable stability of dividend payouts throughout periods of extensive tax changes in the U.S.. Since the stock of capital $K_{t}$ is given at the beginning of each period, the only variables under the control of the firm are the input of labor, $N_{t}$, the dividend payment, $D_{t}$, and the equity issuance $Z_{t}$. Thus, If the dividend constraint is binding, the firm will resort to new equity issuance to finance investment. We follow Gomes (2001) and assume that each additional dollar of new equity implies an additional cost of $\kappa, 0 \leq \kappa \leq$ 1. This cost of equity issuance can be interpreted as transaction costs stemming from capital market frictions which increase the cost of outside capital relative to internally generated funds (Greenwald, Stiglitz, and Weiss, 1984; Myers and Majluf, 1984). Without this constraint, firms could raise enough equity to finance desired investment and the dividend constraint will be useless. Although share repurchases are allowed in the United States, we following the literature (Auerbach, 2002; Desai and Goolsbee, 2004; Gomes, 2001; Gourio and Miao, 2010; Hennessy and Whited, 2005) and impose no share-repurchases constraint for simplicity. In addition, we abstract from debt as in the literature ${ }^{4}$ and assume the firm is all equity financed. Incorporating debt financing would complicate the analysis since we would need to include debt as an additional state variable in the dynamic programming problem of the firm.

\section{B. Financial Frictions and Corporate Taxation}

We start by presenting the optimal decisions of the firm under both lump-sum and proportional taxation, and discuss the financial and the investment policies of the firm later on. When tax is lump-sum, the representative firm's problem is as follows:

\footnotetext{
${ }^{4}$ Auerbach and Hassett (2003), Desai and Goolsbee (2004), and Gourio and Miao (2010), among others, make this choice
} 


\section{Firm's Problem with Lump-sum Taxation}

$$
\max _{\left\{D_{t}, N_{t}, I_{t}, K_{t+1}, Z_{t}\right\}_{t=0}^{+\infty}} \sum_{t=0}^{+\infty} \Lambda_{0, t}\left(D_{t}-Z_{t}\right)
$$

subject to:

$$
\begin{aligned}
D_{t} & =K_{t}^{\alpha} N_{t}^{1-\alpha}+Z_{t}-\kappa Z_{t}-w_{t} N_{t}-I_{t}-\tau_{t} \\
I_{t} & =K_{t+1}-(1-\delta) K_{t} \\
D_{t} & \geq \hat{D} \\
Z_{t} & \geq 0 \\
K_{0} & \text { given }
\end{aligned}
$$

Let $q_{t}, \lambda_{t}^{d}$ and $\lambda_{t}^{z}$ be the Lagrange multipliers associated with the constraints (14b)-(14d), respectively. Using (14a) to eliminate $D_{t}$, the first-order conditions are:

\section{- First Order Conditions}

$$
\begin{aligned}
N_{t} & : \quad w_{t}=(1-\alpha) K_{t}^{\alpha} N_{t}^{-\alpha} \\
I_{t} & : \quad q_{t}=1+\lambda_{t}^{d} \\
K_{t+1} & : \quad q_{t}=\frac{1+\lambda_{t+1}^{d}}{1+r_{t+1}}\left(\alpha K_{t+1}^{\alpha-1} N_{t+1}^{1-\alpha}+1-\delta\right) \\
Z_{t} & : \quad 1=(1-\kappa)\left(1+\lambda_{t}^{d}\right)+\lambda_{t}^{z}
\end{aligned}
$$

The usual transversality conditions and the complementary slackness conditions are omitted from now and onward for simplicity.

\section{Firm's Problem with Proportional Taxation}

When tax is proportional to corporate profit, the firm problem is as follows.

$$
\max _{\left\{D_{t}, N_{t}, I_{t}, K_{t+1}, Z_{t}\right\}_{t=0}^{+\infty}} \sum_{t=0}^{+\infty} \Lambda_{0, t}\left(D_{t}-Z_{t}\right)
$$


subject to:

$$
\begin{aligned}
D_{t} & =\left(1-\tau_{t}\right)\left[K_{t}^{\alpha} N_{t}^{1-\alpha}-w_{t} N_{t}\right]+\tau_{t} \delta K_{t}+(1-\kappa) Z_{t}-I_{t} \\
I_{t} & =K_{t+1}-(1-\delta) K_{t} \\
D_{t} & \geq \hat{D} \\
Z_{t} & \geq 0 \\
K_{0} & \text { given }
\end{aligned}
$$

Let $q_{t}, \lambda_{t}^{d}$ and $\lambda_{t}^{z}$ be the Lagrange multipliers associated with the constraints (17b)-(17d), respectively. Equation (17a) implies that depreciation is tax deductible. Using (17a) to eliminate $D_{t}$, the first-order conditions are:

\section{- First Order Conditions}

$$
\begin{aligned}
N_{t} & : \quad w_{t}=(1-\alpha) K_{t}^{\alpha} N_{t}^{-\alpha} \\
I_{t} & : \quad q_{t}=1+\lambda_{t}^{d} \\
K_{t+1} & : \quad q_{t}=\frac{1+\lambda_{t+1}^{d}}{1+r_{t+1}}\left[\left(1-\tau_{t+1}\right)\left(\alpha K_{t+1}^{\alpha-1} N_{t+1}^{1-\alpha}-\delta\right)+1\right] \\
Z_{t} & : \quad 1=(1-\kappa)\left(1+\lambda_{t}^{d}\right)+\lambda_{t}^{z}
\end{aligned}
$$

\section{Firm's Financial Policy}

Holding the investment decision of the firm unchanged, the financial policy of the firm is determined by equations (15d) (respectively (18d)) under lump-sum (respectively proportional) taxation. The two equations are identical, suggesting that the type of the tax does not matter for the financial decision of the firm, and have the following interpretation: raising one unit of new equity to pay dividends relaxes the dividend constraint and the share repurchase constraint. In addition, when the firm raises one unit of new equity, the shareholder receives $1-\kappa$ because equity issuance involves an additional marginal cost of $\kappa$. Thus, the expression on the right-hand side of equation (18d) gives the marginal benefit to the shareholder. On the other hand, a one-unit increase in new shares lowers equity value by one unit, and the expression on the left-hand side of equation (18d) represents the marginal cost to the shareholder. Equation (18d) requires that the marginal benefit and the marginal cost must be equal at equilibrium. 
If external financing is costless, meaning $\kappa=0$, there is no difference between internal financing and external financing. Equation (18d) implies that $\lambda_{t}^{d}=\lambda_{t}^{z}=0$. In this case, the firm's financial policy is irrelevant. Thus, it does not matter for the firm's value and investment policy how much earnings to retain for use as internal financing, rather than distributing dividends and raising new equity in the external equity market. In this case, the Ricardian equivalence result holds if tax is lump-sum.

In contrast, if new equity issuance is costly, i.e. $\kappa>0$, the firm's financial policy matters. In this case, it follows from equation (18d) that it can not be true that $\lambda_{t}^{d}=\lambda_{t}^{z}=0$. For instance, equation (18d) shows first that if $\lambda_{t}^{d}=0$, then $\lambda_{t}^{z}=\kappa>0$. This means that if the dividend constraint is not binding, then the share repurchase constraint is binding. In other words, it is not optimal for the firm to issue new equity if it is not dividend-constrained because equity issuance is costly. We refer to the case where the dividend constraint is not binding as the internal financing or retained-earnings financing regime. Second, equation (18d) shows that if $\lambda_{t}^{z}=0$, then $\lambda_{t}^{d}=\frac{\kappa}{1-\kappa}>0$. That is, if the firm is issuing new equity, then the dividend constraint is binding. In this case, the firm is in the external financing or equity issuance regime.

In summary, equation (18d) implies that the firm will use external financing if and only if the dividend constraint is binding. The reason is that it is not optimal for the firm to simultaneously distribute more dividend than $\hat{D}$ and issue new equity. In fact, one unit of new equity reduces the equity value by one unit, whereas shareholders receive only $1-\kappa$. If the firm is not dividend-constrained, using retained earnings to finance investment is costless.

\section{Firm's Investment Policy}

For a given financial policy, the firm's investment policy is governed by equations (15c-15b) (respectively (18c-18b)) under lump-sum (respectively proportional) taxation. Equations (18b) and (15b) show that the nature of the tax does not affect the marginal cost of investment, which depends only on the dividend constraint, and the share-repurchase constraint. In other words, the marginal cost of investment depends solely on the marginal source of finance.

If the dividend constraint is binding, the marginal source of finance is new equity. In this case, $Z_{t}>0$ and $\lambda_{t}^{z}=0$. Using equation (18d), $\lambda_{t}^{d}=\frac{\kappa}{1-\kappa}$. We can hence derive the investment equation:

$$
q_{t}=\frac{1}{1-\kappa}
$$


Thus a dividend-constrained firm stops investing when the marginal product of investment, $q_{t}$, equals the cost of financing one additional unit of investment by new equity, $\frac{1}{1-\kappa}$.

On the other hand, if the firm is not dividend-constrained, the marginal source of finance is retained-earnings. In this case, $D_{t}>\hat{D}$ and $\lambda_{t}^{d}=0$. We can derive the investment equation:

$$
q_{t}=1
$$

Thus, the shareholder will stop investing when he or she has no preference between receiving one dollar of additional dividend and investing one dollar in firm's shares. That is, he stops investing when the marginal benefit of investing $q_{t}$ equals the cost of investment. Comparing equations (18b) and (15b) reveals that the marginal cost of investment is higher in an equity-issuing regime than in an internal-financing regime.

We now turn to the effect of corporate tax on investment. To this end, we use (15b-15c), respectively (18b-18c), to obtain the optimal investment condition (21), respectively (22), when tax is lump-sum, respectively proportional to corporate profit.

$$
\begin{gathered}
1+\lambda_{t}^{d}=\frac{1+\lambda_{t+1}^{d}}{1+r_{t+1}}\left(\alpha K_{t+1}^{\alpha-1} N_{t+1}^{1-\alpha}+1-\delta\right) \\
1+\lambda_{t}^{d}=\frac{1+\lambda_{t+1}^{d}}{1+r_{t+1}}\left[\left(1-\tau_{t+1}\right)\left(\alpha K_{t+1}^{\alpha-1} N_{t+1}^{1-\alpha}-\delta\right)+1\right]
\end{gathered}
$$

Under lump-sum taxation, equation (21) shows that the tax policy influences investment only if it changes the marginal source of finance between two adjacent periods. In fact, if the current and the next marginal sources of finance are new equity, i.e $\lambda_{t}^{z}=\lambda_{t+1}^{z}=0$ (implying $\lambda_{t}^{d}>0$ and $\lambda_{t+1}^{d}>0$ ), then $1+\lambda_{t}^{d}=1+\lambda_{t+1}^{d}=\frac{1}{1-\kappa}$. Similarly, if the current and the next marginal sources of finance are retained-earnings, i.e $\lambda_{t}^{d}=\lambda_{t+1}^{d}=0$. In both cases, the factors $1+\lambda_{t}^{d}$ and $1+\lambda_{t+1}^{d}$ cancel out in equation(21).

In contrast, tax policy affects investment policy even if the marginal source of finance remains unchanged when tax is proportional to business profits. More precisely, a tax cut financed by a tax increase one period later will reduce the expected marginal after-tax return on investment while the marginal cost of investment remains unchanged. In response, the firm will reduce investment.

Now, let us consider a situation where a tax cut changes the marginal source of finance between two adjacent periods. Assume that the firm is initially constrained and the tax cut is enough to temporarily relax the constraint, and the tax increase is such that the dividend constraint 
binds again. In this case, the firm uses internal cash-flow at the period of tax cuts but switches to external financing one period later. Under lump sum taxation, the tax cuts temporarily reduce the marginal cost of investment from $\frac{1}{1-\kappa}$ to 1 . Since the tax policy does not affect the expected marginal return on investment, current investment should increase. When tax is proportional to corporate profits, two forces are present. The marginal cost of investment from $\frac{1}{1-\kappa}$ to 1 as before, but the higher future tax rate pins down the after-tax return on current investment. Thus, the net effect on investment will depend on the relative intensity of each force. If the expected reduction in the return on investment is more than proportional to the reduction in the marginal cost of investment, investment will decrease. Otherwise, investment will increase because the decrease in the marginal cost of investment more than fully offsets the reduction in after-tax return on investment. Equation (19) indicates that the higher the marginal cost of equity issuance, the higher the positive effect will be.

\section{E. Other Agents' Problems}

The household's problems under the two types of tax are identical to the household problem in the basic framework. In contrast, under proportional taxation the government problem changes as follows:

$$
R_{t} B_{t}+G=\tau_{t}\left[K_{t}^{\alpha} N_{t}^{1-\alpha}-w_{t} N_{t}-\delta K_{t}\right]+B_{t+1}
$$

Again, it may run a deficit in the short to medium term, but is not allowed to play a Ponzi game with other agents. Accordingly, its inter-temporal budget constraint is:

$$
B_{0}+G \sum_{t=0}^{+\infty} \prod_{i=0}^{t} R_{i}^{-1}=\sum_{t=0}^{+\infty} \prod_{i=0}^{t} R_{i}^{-1} \tau_{t}\left[K_{t}^{\alpha} N_{t}^{1-\alpha}-w_{t} N_{t}-\delta K_{t}\right]
$$

\section{Model Solution}

We use the closed-form solution to determine the long run equilibrium of the model. Next, we fix a length for the transition and solve for the transitional dynamics following the tax cut by backward induction. The detailed algorithm is presented in annex B. Focusing on a steady state with zero government debt, we first derive some properties of the long-run equilibrium necessary to parameterize the model in a way that ensures the feasibility of the tax experiments undertaken later on. 


\section{A. Steady State Properties ${ }^{5}$}

Proposition 2. The optimal steady state stock of capital does not depend on the lower bound on dividend.

Proposition 3. A higher proportional tax rate implies lower capital stock at steady state while lump-sum tax does not affect long-run capital stock.

Proof: With lump-sum tax: $K_{s s}^{\text {lump }}=\left(\frac{\alpha \beta}{1-\beta(1-\delta)}\right)^{\frac{1}{1-\alpha}}$. Under proportional tax: $K_{s s}^{\text {prop }}=\left[\frac{\alpha \beta(1-\bar{\tau})}{1-\beta+\delta \beta(1-\bar{\tau})}\right]^{\frac{1}{1-\alpha}}$ and $\frac{\partial K_{s s}^{\text {prop }}}{\partial \bar{\tau}}<0$.

Lemma 1. Under lump-sum tax, a government spending $G$ is feasible at a zero debt steady state if and only if $G<\hat{G}_{l}$, with:

$$
\hat{G}_{l}=\left(\frac{\alpha \beta}{1-\beta(1-\delta)}\right)^{\frac{\alpha}{1-\alpha}}\left[(1-\alpha)(1-\kappa)+\frac{\alpha(1-\beta)}{(1-\beta(1-\delta))}\right]-\hat{D} \kappa
$$

Lemma 1 shows that under lump-sum tax, it is not feasible to finance more than $\hat{G}_{l}$ in a sustainable way even when the firm produces optimally and all the production is entirely devoted to finance government spending.

Assumption 1. $\hat{D} \leq \hat{D}_{l}^{h i} \equiv \frac{1-\beta}{\beta}\left(\frac{\alpha \beta}{1-\beta(1-\delta)}\right)^{\frac{1}{1-\alpha}}$.

Proposition 4. Under tax is lump-sum, $\hat{D}_{l}^{\text {hi }}$ is the interest rate times the steady-state capital stock. If assumption 1 is violated, the firm will be constrained at steady state regardless of the size of the government.

Proposition 5. Let assumption 1 hold. The firm issues equity if and only if $G>\bar{G}_{l} \equiv \hat{D}_{l}^{h i}-\hat{D}$. $\bar{G}_{l}$ is the maximum government revenue that does not distort the firm investment.

Assumption 2. $\hat{D}<\hat{D}_{l}^{l o} \equiv-(1-\alpha)\left(\frac{\alpha \beta}{1-\beta(1-\delta)}\right)^{\frac{\alpha}{1-\alpha}}$.

Proposition 6. Assume that assumption 2 holds. Then, $\bar{G}_{l}<\hat{G}_{l}$, i.e., there exists a range of feasible government size which constrains the firm to use equity as a marginal source of investment financing.

Lemma 2. Under proportional taxation, there exists a threshold $\hat{\tau}_{p}, 0<\hat{\tau}_{p}<1$ such that the total tax revenue is increasing (respectively decreasing) in $\tau$ if and only if $\tau<\hat{\tau}_{p}$ (respectively $\left.\tau>\hat{\tau}_{p}\right)$. The maximum tax revenue that government can collect in a zero debt steady state using proportional tax is: $\hat{G}_{p}=\alpha(1-\alpha)\left(\frac{\alpha^{2} \beta}{1-\beta+\delta \beta}\right)^{\frac{\alpha}{1-\alpha}}$ with $\hat{\tau}_{p} \equiv \frac{(1-\beta+\delta \beta)(1-\alpha)}{1-\beta+\delta \beta(1-\alpha)}$.

\footnotetext{
${ }^{5}$ Detailed proofs of all results derived here are given in Annex A.2.
} 
Lemma 2 defines the well known Laffer Curve for this problem.

Proposition 7. Let $\hat{D}_{p}^{l o} \equiv \frac{1-\beta}{\beta}\left[\frac{\alpha^{2} \beta}{1-\beta+\alpha \delta \beta^{2}+\delta \beta-\delta \beta^{2}}\right]^{\frac{1}{1-\alpha}}$ and

$\hat{D}_{p}^{h i} \equiv \frac{1-\beta}{\beta}\left(\frac{\alpha}{\delta}\right)^{\frac{1}{1-\alpha}}$. For $\alpha, \beta, \delta, \kappa$ satisfying $0<\alpha, \beta, \delta, \kappa<1: \hat{D}_{l}^{l o}<\hat{D}_{p}^{l o}<\hat{D}_{l}^{h i}<\hat{D}_{p}^{h i}$.

Assumption 3. Assume that: $\hat{D}<\hat{D}_{l}^{h i}=\frac{1-\beta}{\beta}\left(\frac{\alpha \beta}{1-\beta(1-\delta)}\right)^{\frac{1}{1-\alpha}}$.

Proposition 8. If assumption 3 holds, there exists a critical tax rate $\bar{\tau}_{p}, 0<\bar{\tau}_{p}<1$ such that the firm will be dividend-constrained under proportional taxation if and only if:

$$
\tau>\bar{\tau}_{p} \equiv \frac{\alpha \beta^{\alpha}(1-\beta)^{1-\alpha}-\hat{D}^{1-\alpha}(1-\beta+\delta \beta)}{\alpha \beta^{\alpha}(1-\beta)^{1-\alpha}-\delta \beta \hat{D}^{1-\alpha}}
$$

and the corresponding government spending is: $\bar{G}_{p}=\alpha\left(\frac{\beta \hat{D}}{1-\beta}\right)^{\alpha}-\frac{\delta \beta \hat{D}}{1-\beta}-\hat{D}$.

Assumption 4. Assume that: $\hat{D}_{p}^{l o}<\hat{D}<\hat{D}_{p}^{h i}$.

Lemma 3. Let assumption 4 hold. Then, $0<\bar{\tau}_{p}<\hat{\tau}_{p}<1$.

When assumption 3 holds, proposition 8 derives the tax rate, $\bar{\tau}_{p}$, above which the firm will be forced to issue new equity to finance investment under proportional taxation. Lemma 3 has some important implications for the policy experiments considered in this paper. It provides sufficient conditions on dividend targets that guarantee the existence of a feasible tax rate such that the dividend constraint is binding at initial steady state.

\section{B. Parameterization and Numerical Algorithm}

The parameter values are set to illustrate the workings of the model and do not necessarily intend to match firms dynamics in the data, but we still require them to be within the range of values estimated or calibrated by other studies in the literature. To allow a credible comparison of the effects of temporary tax cuts under lump-sum and proportional taxes, it is meaningful to consider tax cuts which imply the same reduction in government revenue. To reach the objective, one easy way is to set the lump-sum tax rate equal to the tax revenue generated by the proportional tax rate. Proposition 7 ensures that it is feasible to consider such tax cuts experiments starting from initial steady-states where the dividend constraint is binding. The parameters can be classified in two groups. The top panel of Table 1 indicates those defined a priori. We assume that a time-period in the model corresponds to one year in the data and 
set the discount factor to 0.96 , consistently with the annual interest rate of $4 \%$ used in the literature. The capital share is set to $1 / 3$ as in the macroeconomic literature. Using the steady-state properties derived in subsection IV.A, we calibrate the values of the remaining parameters, summarized in the bottom panel of Table 1, to serve primarily three objectives:

- The set of feasible tax rates for which the dividend constraint is binding ( not binding) under both lump-sum and proportional taxation is not empty.

- The set of feasible policy experiments under which the firm is constrained at the initial steady-state, becomes unconstrained after tax cut, and constrained at the period of tax increase is not empty.

- The tax rate when tax is proportional to business profit, including at the period of tax increase, always falls in the increasing portion of the Laffer Curve.

Table 1. Baseline Parameterization

\begin{tabular}{lcc}
\hline Description & Parameter & Value \\
\hline Capital income share & $\alpha$ & 0.33 \\
Discount factor & $\beta$ & 0.96 \\
\hline Depreciation rate & $\delta$ & 0.101 \\
Marginal cost of external financing & $\kappa$ & 0.027 \\
Lower Bound on Dividend & $\hat{D}$ & 0.113 \\
\hline
\end{tabular}

The result implies a marginal cost of external financing, $\kappa=0.027$, close to the estimated value of 0.028 by Gomes (2001). All together, the parameters values imply that the proportional tax rate, $\bar{\tau}_{p}$, above which the firm is dividend-constrained at steady state is equal to the highest US federal statutory corporate rate of $39 \%$. This tax rate is high enough so that large tax cuts which allow temporary switching of financing regimes are feasible under both lump sum and proportional taxation. The threshold of proportional tax rate, $\hat{\tau}_{p}$, corresponding to the maximum feasible government spending is equal to $87 \%$. These tax rates imply that the set of feasible tax rates, for which the dividend constraint is binding at steady state under both lump-sum and proportional taxes, is non-empty (] $\bar{\tau}_{p}, \hat{\tau}_{p}[\neq\{\phi\})$. In addition, $\bar{\tau}_{p}$ is located on the upward section of the Laffer Curve $\left(\bar{\tau}_{p}<\hat{\tau}_{p}\right)$, ensuring that there is room to simulate policy experiments in which firms are initially constrained. 
Figure 1 plots the evolution of tax revenue as a function of the proportional tax rate for parameters used in this paper. The blue and red lines in the figure plot the tax rates $\bar{\tau}_{p}$, and $\hat{\tau}_{p}$, respectively.

Figure 1. Laffer Curve

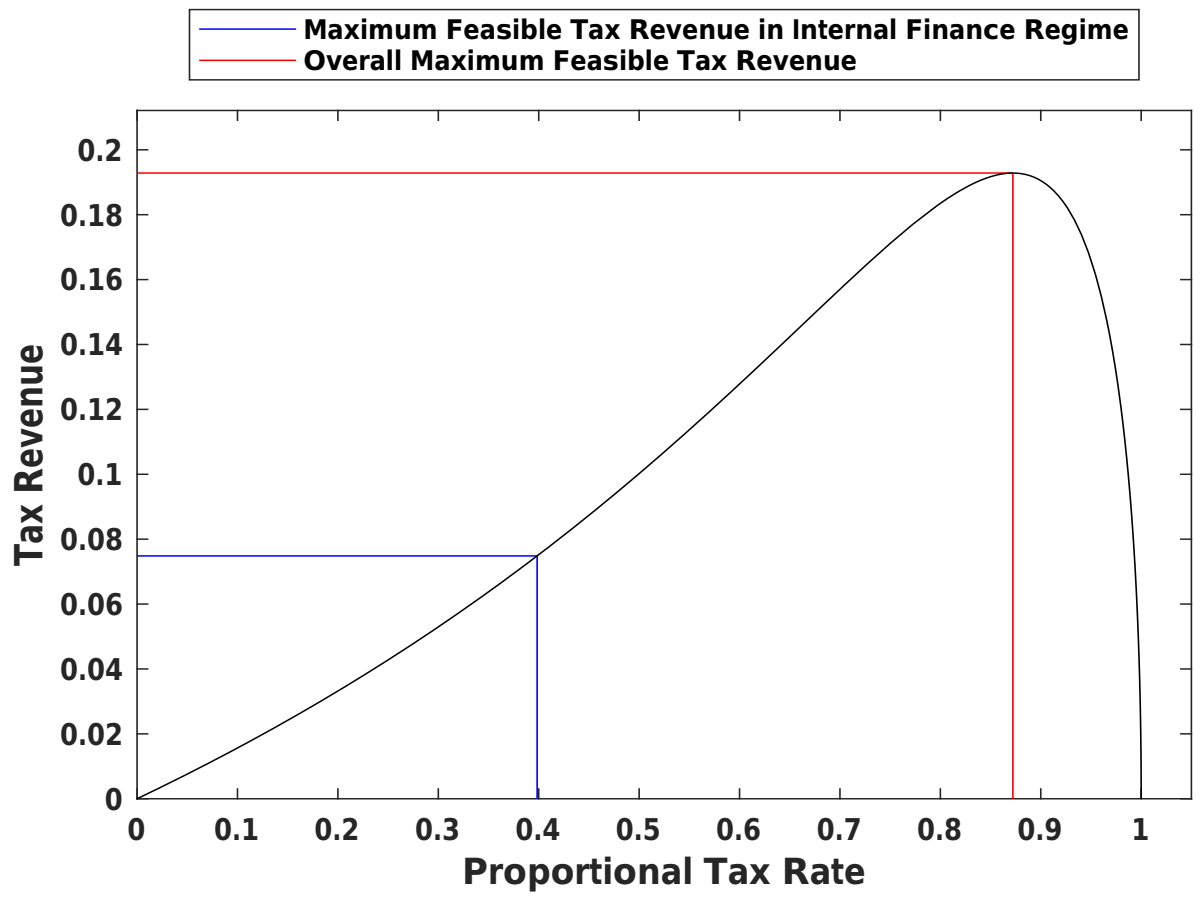

V. Effects of Temporary Tax Cuts

\section{A. Policy Experiments}

We assume exogenous and time-invariant government spending, and zero government debt in steady-state to isolate eventual effects associated with changes in government size. Figure 2 presents a typical experiment in which the government uses a lump-sum tax to raise revenue. The blue solid line represents the tax level corresponding to the maximum feasible government spending. The black line is the tax level at steady state and is equal to the exogenous size of the government. The blue dashed line refers to the critical level of tax above which the dividend constraint is binding at steady state. The green line shows the evolution of the government debt. The economy is initially in a steady-state where the dividend constraint is binding. At period 2, the government unexpectedly cuts tax, large enough to relax the dividend constraint. The firm then temporarily switches to a retained-earnings financing regime. The government 
issues one-period debt to finance the deficit induced by the tax cut. Once the tax cut occurs, all agents have perfect foresight about the future tax path. At period 3, the government increases tax to repay its debt and related service. From period 3 and onward, the economy goes through a transition but converges to the initial steady state because the tax and the government debt revert to their steady-state values after period 4.

Figure 2. Illustration of Tax Policy Experiment (lump-sum tax)

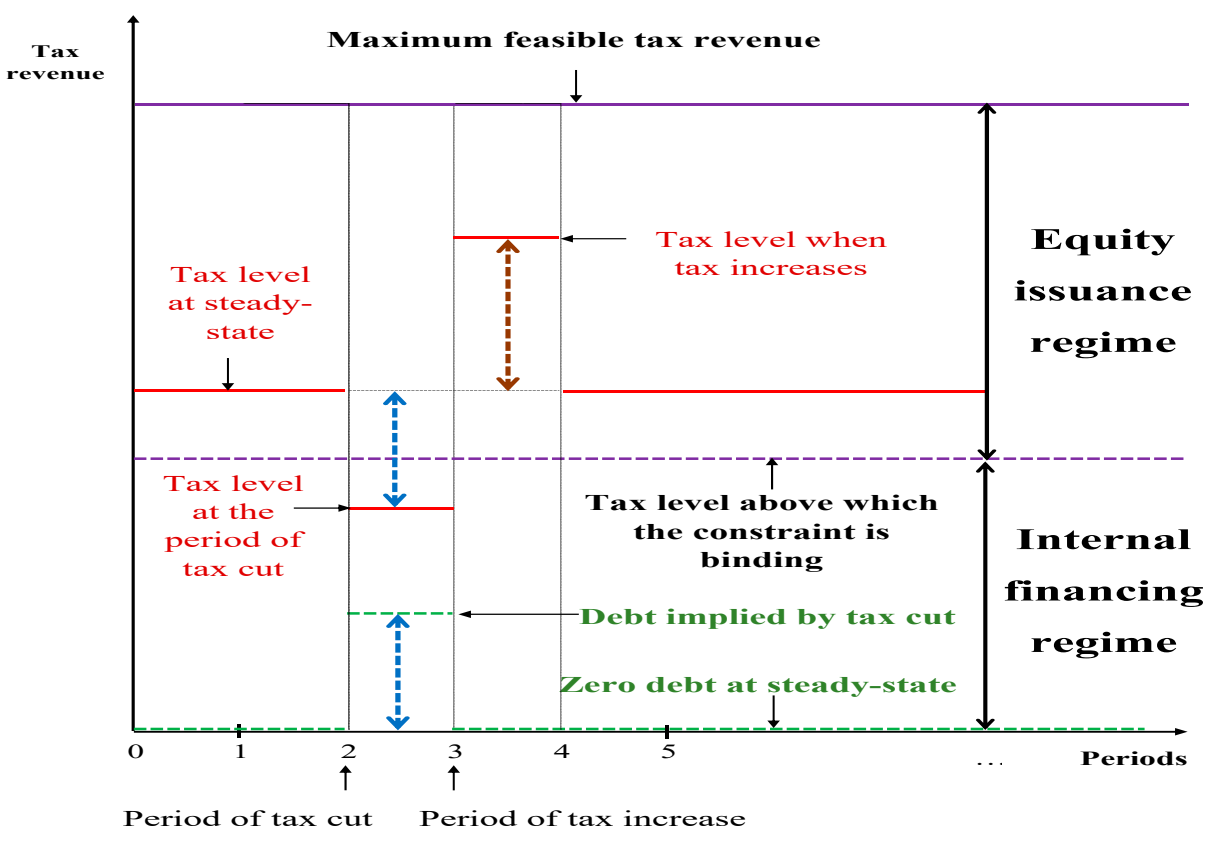

We perform several tax experiments to assess the theoretical implications of the model. Table 2 presents the description of all experiments. Tax is lump-sum in experiments 1 and 2 and proportional in experiments 3 to 7 . To ensure comparability, we set the lump-sum tax rates under experiments 1 and 2 to equal the government revenue under experiments 3 and 4 when tax is proportional, respectively. In experiments 1 and 3, the steady-state tax rate is chosen so that the firm is initially unconstrained. Thus, the tax cuts do not imply a change in the marginal source of finance between two adjacent periods. In this case, any differences between the dynamics of the economy after policy experiments 1 and 3 should be fully explained by the distortionary effects of the proportional tax. In the other experiments, the firm is initially 
Table 2. Description of Experiments

\begin{tabular}{|c|c|c|c|c|c|c|c|}
\hline & \multicolumn{2}{|c|}{ Lump-sum tax* } & \multicolumn{5}{|c|}{ Proportional tax } \\
\hline & 1 & 2 & 3 & 4 & 5 & 6 & 7 \\
\hline Steady-state rate & 16.35 & 52.50 & 15.00 & 41.00 & 41.00 & 41.00 & 41.00 \\
\hline Tax rate at the period of tax cut & 10.58 & 5.14 & 10 & 5.00 & 5.00 & 5.00 & 5.00 \\
\hline Equity issuance cost $\kappa$ & 0.027 & 0.027 & 0.027 & 0.027 & 0.01 & 0.04 & 0.06 \\
\hline Constraint Status initially** & NB & B & NB & B & B & B & $B$ \\
\hline Constraint Status after tax cut & NB & NB & NB & NB & NB & NB & NB \\
\hline
\end{tabular}

Note: *The lump-sum tax rate in column 1 (respectively 2 ) is the tax revenue implied by the proportional tax rate in column 3 (respectively 4) divided by the before-investment profit of the firm.

** $B$ refers to Binding constraint while NB refers to Non-Binding constraint.

in the equity issuance regime and the tax cuts temporarily relax the constraint on the firm, allowing it to temporarily switch to a retained-earnings financing regime. All differences between the dynamics of the economy under experiments 1 and 2 are due to the presence of financing frictions.

\section{B. Transitional Dynamics After Tax Cuts}

Figures 3 and 4 present the transitional dynamics of the economy after tax cuts. In all experiments, the economy takes at most 20 periods to converge back to steady-steady-state. The black (red) lines plot the dynamics of the economy under lump-sum (proportional) taxation. In each panel, the horizontal axis measures the time period. The vertical axes measure the absolute values in the first column, and the percentage deviation from the initial steady state before the tax cuts in the last column.

Let's start with Figure 3 which plots the dynamics of the economy in experiments 1 and 3. The economy is initially in a steady state where the firm is in the internal finance regime. The government reduces the proportional tax rate from its initial $15 \%$ to $10 \%$ at period 2 . Under both lump-sum and proportional tax, this policy does not change the marginal source of financing. Since external financing is costly and the firm is not dividend-constrained, it stays in the internal financing regime and equity issuance is equal to zero during the whole transition.

When the tax is lump-sum, the black line shows that the firm devotes all the tax cut to dividend payment at the period of tax cut . It keeps its investment plan unchanged because the lump-sum tax affects neither the marginal cost, nor the return on investment. As the after interest rate 
is unchanged, the tax cut does not distort the inter-temporal consumption decisions of the household. Accordingly, the household maintains its consumption plan unchanged and invests all the extra dividend in government bonds. When tax increases one period later, the firm reduces dividend payments by the additional tax liability and keeps its investment plan unchanged. The household uses its savings plus interest to maintain its consumption path unchanged. As a result, all the adjustment takes place through the dividend policy of the firm.

The red line shows that under proportional tax, the firm reduces investment and increases dividends by more than the total amount of the tax cut. This behavior is explained by the effect of the tax cut on the future tax policy. In fact, the expectation of higher tax in the future reduces the after-tax return on current investment. This expectation of low after-tax returns on investment provides disincentives for firm's investment in capital. As after-tax interest rate falls, households are induced to save less and to consume more. As a result, a temporary cut in proportional corporate profit tax boosts consumption at the expense of lower investment. These investment dynamics are consistent with the findings of previous research. For instance, Dotsey (1994) finds that a temporary cut on capital tax, followed by a tax increase, reduces investment.

In summary, the firm behaves in a Ricardian fashion when the tax is lump-sum and the dividend constraint is not binding. However, the expectation of future high tax rate reduces investment under proportional taxation.

Now, we consider a situation where the financing constraint is binding in the initial equilibrium. As described in Table 2, the economy is initially in a steady state where the tax rate equals $41 \%$ and the firm is dividend-constrained. Then, the government cuts tax to 5\%. This tax relief is large enough to temporarily release the dividend constraint under both lump-sum and proportional taxes. Figure 4 plot the dynamics of the economy under lump-sum and proportional tax, respectively. It shows that in the initial steady state, dividend payments are equal to the lower bound and the firm finances investment by issuing new equity. At period 2 when tax decreases, the additional cash-flows provided by the tax cuts allow the firm to increase dividend payments above the lower bound. Thus, the firm switches from the equity-issuance regime to the internal financing regime and temporarily experiences the lower marginal cost of investment. Equity issuance falls to zero under both taxes at this period. Moreover, the decrease in investment cost increases the net return on investment and provides incentives to the firm to investment more in capital. In response, the firm devotes almost all the tax cut to investment. Under lump-sum taxation, the black line in Figure 4 shows that investment rises initially by about $8 \%$, then 
Figure 3. Transitional Dynamics without Financing Frictions
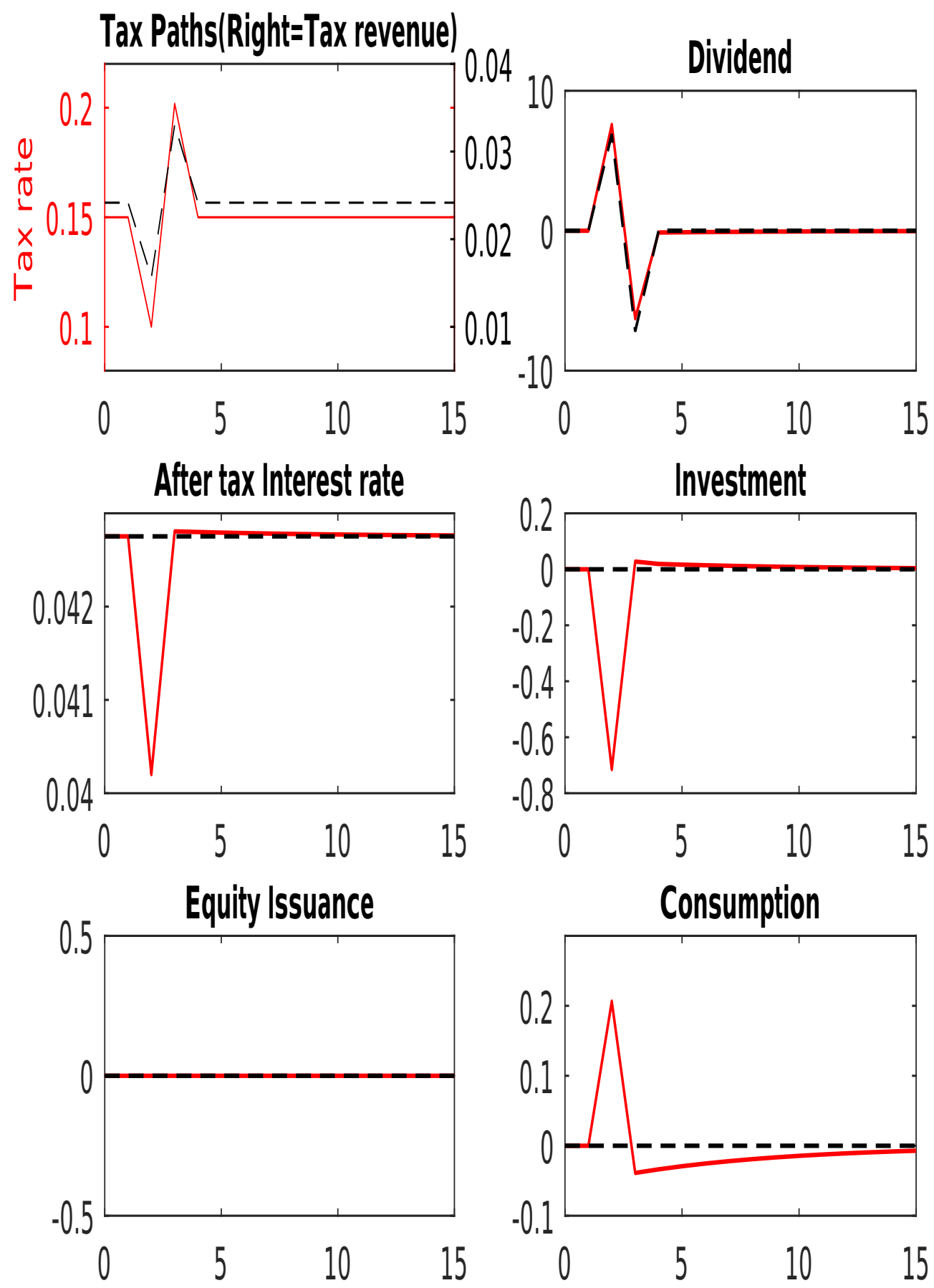

declines below its steady-state level when tax increases and gradually rises to the steady-state level. However, investment increases by less than $1 \%$ when the tax is proportional to business profit. The reason is that when tax is distortionary, the future high tax rate reduces the expected after-tax return. This expectation of lower after-tax return on investment counteracts the positive 
Figure 4. Transitional Dynamics with Financing Frictions

Tax Paths (Right=Tax revenue)
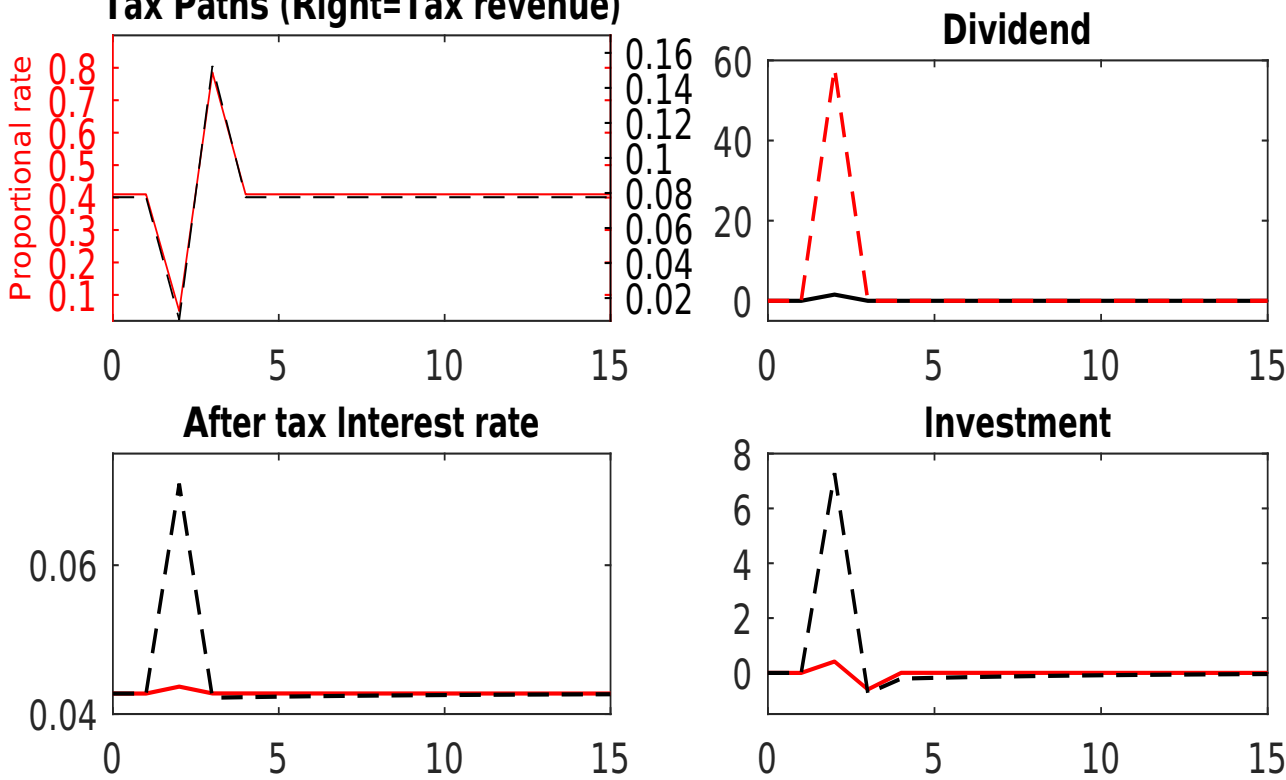

Equity Issuance
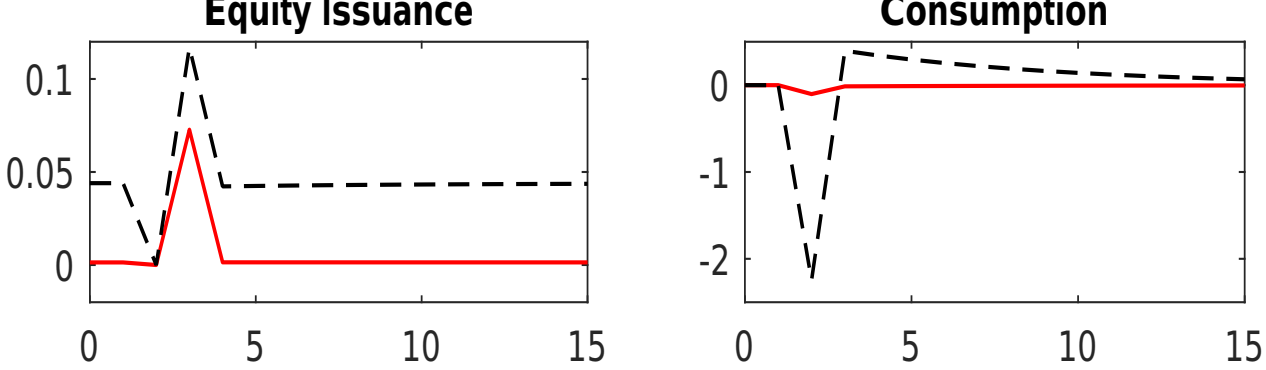

effects of lower marginal investment cost. In response, the firm increases dividends relatively more than in an economy with lump-sum taxation. In the benchmark simulation, the increase in the net return on investment induced by the decrease in the marginal investment cost dominates the investment disincentives generated by the expectation of future high tax rate. As a result, the net investment effect is positive. Under both lump sum and proportional taxes, higher demand of capital puts upward pressure on interest rate inducing the household to consume less and to save more in government bonds. From period 3 to the steady state, the firm switches back to the equity-issuance regime. The marginal cost of investment increases and the firm reduces investment. In response, interest rate falls at period 3 and converges monotonically to the steady-state. Consumption jumps above the steady state when tax rises before declining monotonically to the steady state.

In a nutshell, temporary cuts in lump-sum tax stimulate investment because they reduce the marginal investment cost by allowing firms to avoid the additional cost associated with external 
financing. When the tax is proportional, this effect is mitigated by the expectation of higher future taxes, which reduce the after-tax return on investment. In the benchmark calibration, the positive effects of the tax cuts more than offset the adverse effects of future tax rate and investment increases.

\section{Sensitivity analysis}

From the analysis above, the response of investment to temporary reduction in proportional corporate profit tax is driven by two forces. First, the tax cut temporarily reduces the marginal cost of investment because the additional cash flow provided by the tax relief allows the firm to switch to the internal financing regime. The size of this effect highly depends on the extent of the investment distortion in the economy before the tax cut, which is proportional to the marginal cost of external financing. Second, the expectation of future high tax rate reduces the expected net return on current investment. As the first effect provides incentives to invest while the latter one discourages investment, the net effect of temporary tax cut on investment depends on the relative strength of each force. In this section, we discuss the sensitivity of the investment response to the amount of frictions in the economy.

More precisely, we consider proportional corporate profit taxes and simulate the dynamics of the economy following a reduction of the tax rate from $41 \%$ to $5 \%$ for three different values of the marginal cost of external financing. We consider values of equity issuance cost in the range of those used ${ }^{6}$ by the macroeconomic literature, $\kappa \in\{0.01,0.04,0.06\}$. As we start from the same initial tax rate, implement the same amount of tax cut and the government spending is time-invariant, the implied government debt is identical across experiments. ${ }^{7}$ Therefore, any difference in the investment dynamics between the three experiments fully results from the difference in the cost of equity-issuance.

The black, the red and the blue lines in Figure 5 plot the dynamics of the economy when the cost of equity issuance per dollar of external funding is 1, 4 and 6 cents, respectively. In each panel, the horizontal axis measures the time period. The vertical axes measure the absolute value in the left panel, and the percentage deviation from the steady state in the right

\footnotetext{
${ }^{6}$ (Gomes, 2001), Altinkilic and Hansen (2000) and Hennessy and Whited (2005) estimate the cost of external financing equal to $0.028,0.0515$ and 0.0509 , respectively. Gourio and Miao (2011) set $\kappa$ equals to 0.03 .

${ }^{7}$ The total tax revenue at any period is given by $\tau_{t}\left[K_{t}^{\alpha} N_{t}^{1-\alpha}-w_{t} N_{t}-\delta K_{t}\right]=\tau_{t}\left[\alpha K_{t}^{\alpha} N_{t}^{1-\alpha}-\delta K_{t}\right]$. The government debt implied by the tax cut, $\Delta \tau\left[\alpha K^{\alpha}-\delta K\right]$ as $N_{t}=1$, then depends only on the stock of the pre-determined level of capital stock.
} 
Figure 5. Sensitivity analysis
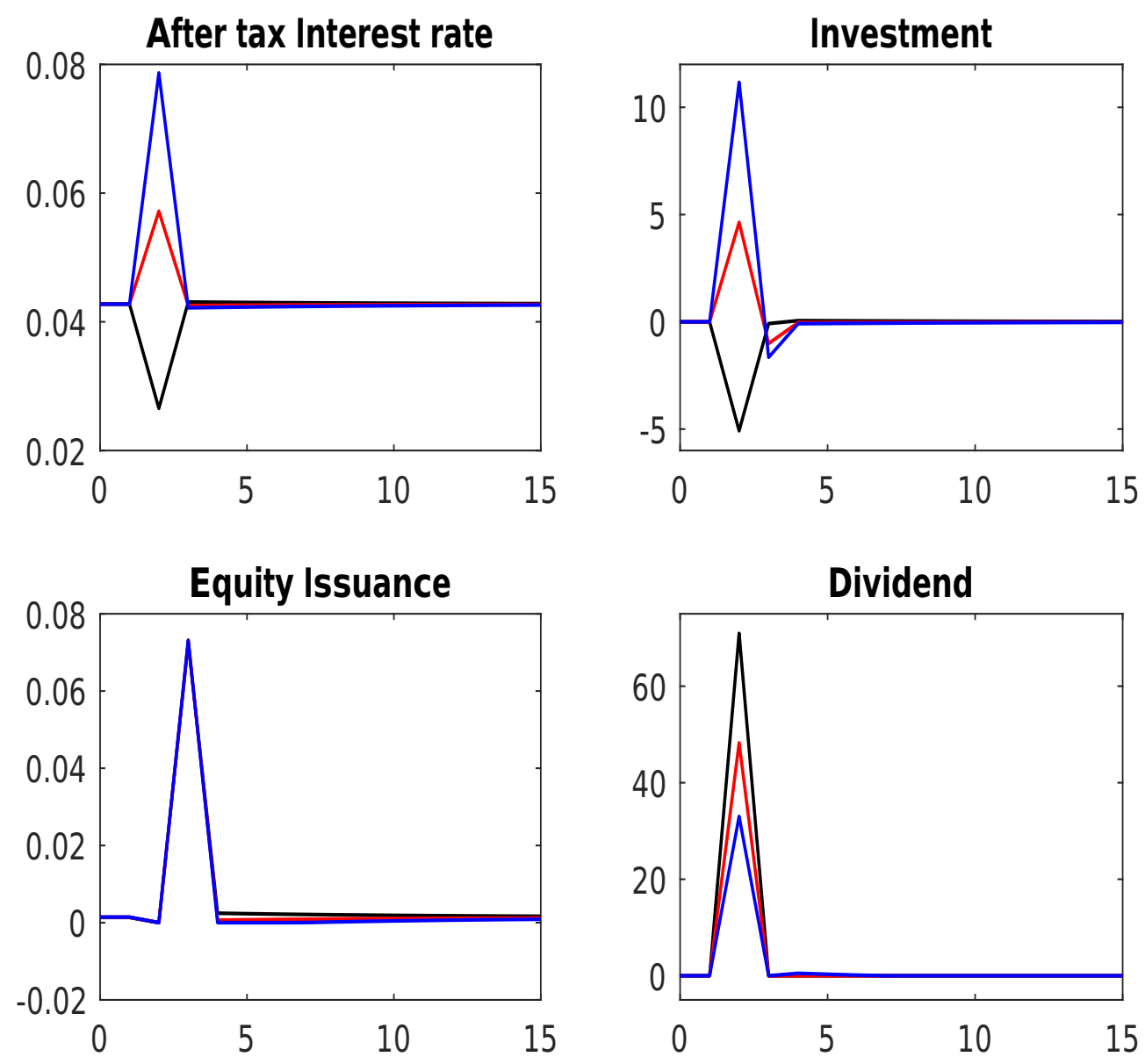

panel. Figure 5 shows that at period 2 when government cuts tax, the firm increases dividend payment above the lower bound in all experiments. Consequently, it temporarily switches from the external financing regime to the internal financing regime. One period later when tax increases, equity issuance increases beyond the steady-state level and falls monotonically to steady state.

The main goal in this section is to explain the difference in the firm's responses between the three simulations in period 2. For instance, Figure 5 shows that the size of the increase in dividend payments varies with the marginal cost of equity issuance. Dividend payments increase by about $70 \%, 50 \%$ and $35 \%$ when $\kappa$ is $0.01,0.04$, and 0.06 , respectively. Furthermore, investment increases by around $10 \%$ and $5 \%$ if raising one dollar of new equity costs 6 and 4 cents for the firm. However, it decreases by more than $3 \%$ when the cost of external financing equals 1 cent per dollar of new equity issued. The logic behind this result is the following. The investment incentives provided by the tax cut depends solely on the extent of investment 
distortion in the economy before the tax, which is determined by the marginal cost of equity issuance, $\kappa$. More precisely, the higher the marginal cost of equity issuance, the higher is the reduction in the marginal cost of investment, and hence the incentives from the temporary tax relief. Consequently, for lower values of $\kappa$, the negative effects of lower after-tax return dominate the direct incentives of the tax relief. In response, the firm decreases investment. As the marginal cost of equity issuance increases, the direct benefits of tax cuts increase and offset the disincentives from expectations of higher future taxes. Accordingly, investment increases. Consistent with this reasoning, Figure 5 shows that the firm decreases investment for $\kappa=0.01$, while it increases investment when $\kappa=0,06$ than if $\kappa=0.04$.

\section{Conclusion}

This paper studies the effects of temporary business tax cuts on investment and output. We analyze the full transition of the economy following temporary tax cuts financed by future tax increases using a simple dynamic general equilibrium model in which a representative firm makes investment and financing decisions potentially subject to equity issuance costs and a dividend constraint. We first establish that firms behave in a Ricardian fashion when capital markets are perfect (or financing constraints are not binding) and taxes are lump-sum. When taxes are lump-sum, the policy affects firms' decisions only if it changes the marginal source of finance between two adjacent periods. In the absence of binding financing constraints, temporary tax cuts provide incentives to current consumption, crowding out investment if taxes are proportional to businesses' profits because firms anticipate higher taxes in the future.

When the firm is initially dividend-constrained, the effects depend, both qualitatively and quantitatively, on the tax instrument used, the size of the tax cuts, and the amount of investment distortion in place before the tax cuts. These results suggest that temporary tax incentives should be carefully designed (size and instrument), and well-targeted (to potentially constrained firms) to maximize the stimulative benefits of the policy.

For instance, tax cuts which temporarily relax the internal financing constraints, boost investment at the cost of a contraction in consumption if taxes are lump-sum. Under proportional business taxes, the net effect is driven by two opposite forces. On one hand, switching from an equity-issuance regime to an internal financing regime reduces the marginal cost of investment, providing incentives to investment. On the other hand, current tax cuts imply future tax increases, lowering expected after-tax marginal benefit of investment. The size as well as the sign of the net effect on investment depends on the relative strength of each effect. The results highlight that for a 
given amount of tax cuts, the higher the marginal cost imposed by the financing constraint, the higher is the positive effect on investment.

The analysis in this paper could be extended along a few directions. Particularly, firms are heterogenous in several dimensions. Thus, at any point in time, different firms may be in different financing regimes and respond to temporary corporate tax cuts in different ways. Therefore, one would ideally study the policy experiment in an environment with firm heterogeneity. Considering firm heterogeneity would allow incorporating further characteristics of firms dynamics observed in the data, thereby offering a better laboratory to quantify the effects of temporary corporate tax reliefs. 


\section{REFERENCES}

Abel, Andrew, 1982, "Dynamic effects of permanent and temporary tax policies in a q model of investment," Journal of Monetary Economics, Vol. 9, No. 3, pp. 353-373.

Allen, Franklin, and Roni Michaely, 2003, "Payout policy," in G.M. Constantinides, M. Harris, and R. M. Stulz (eds.), Handbook of the Economics of Finance, Handbook of the Economics of Finance, Vol. 1, chap. 7, pp. 337-429 (Elsevier).

Altinkilic, Oya, and Robert S. Hansen, 2000, "Are there economies of scale in underwriting fees? Evidence of rising external financing costs," Review of Financial Studies, Vol. 13, No. 1, pp. 191-218.

Auerbach, Alan, and Kevin Allen Hassett, 2003, "On the marginal source of investment funds," Journal of Public Economics, Vol. 87, No. 1, pp. 205-232.

Auerbach, Alan, and James R. Hines, 1987, "Anticipated Tax Changes and the Timing of Investment," pp. 163-200.

Auerbach, Alan, and Laurence J. Kotlikoff, 1987, "Evaluating Fiscal Policy with a Dynamic Simulation Model," American Economic Review, Vol. 77, No. 2, pp. 49-55.

Auerbach, Alan J, 2002, “Taxation and corporate financial policy," Handbook of public economics, Vol. 3, pp. 1251-1292.

Barro, Robert J., 1974, “Are Government Bonds Net Wealth?” Journal of Political Economy, Vol. 82, No. 6, pp. pp. 1095-1117.

Bianchi, Javier, 2016, "Efficient Bailouts?” American Economic Review, Vol. 106, No. 12, pp. 3607-59.

Bohn, Henning, 1990, “Tax Smoothing with Financial Instruments," American Economic Review, Vol. 80, No. 5, pp. 1217-30.

Desai, Mihir A, and Austan Goolsbee, 2004, "Investment, overhang, and tax policy," Brookings Papers on Economic Activity, Vol. 2004, No. 2, pp. 285-355.

Dotsey, Michael, 1994, "Some unpleasant supply side arithmetic," Journal of Monetary Economics, Vol. 33, No. 3, pp. 507-524.

Gomes, Joao F, 2001, "Financing investment," American Economic Review, pp. 1263-1285.

Gourio, François, and Jianjun Miao, 2010, "Firm Heterogeneity and the Long-Run Effects of Dividend Tax Reform," American Economic Journal: Macroeconomics, Vol. 2, No. 1, pp. 131-68.

—_ 2011, “Transitional Dynamics of Dividend and Capital Gains Tax Cuts," Review of Economic Dynamics, Vol. 14, No. 2, pp. 368-383.

Greenwald, Bruce, Joseph E. Stiglitz, and Andrew Murray Weiss, 1984, "Informational Imperfections in the Capital Market and Macroeconomic Fluctuations," American Economic Review, Vol. 74, No. 2, pp. 194-99. 
Heathcote, Jonathan, 2005, "Fiscal Policy with Heterogeneous Agents and Incomplete Markets," Review of Economic Studies, Vol. 72, No. 1, pp. 161-188.

Hennessy, Christopher A, and Toni M Whited, 2005, "Debt dynamics," The Journal of Finance, Vol. 60, No. 3, pp. 1129-1165.

Mankiw, Gregory, and Matthew Weinzierl, 2006, "Dynamic scoring: A back-of-the-envelope guide,” Journal of Public Economics, Vol. 90, No. 8-9, pp. 1415 - 1433.

Modigliani, F., and M.H. Miller, 1958, “The cost of capital, corporation finance and the theory of investment," The American Economic Review, Vol. 48, No. 3, pp. 261-297.

Myers, Stewart C, and Nicholas S Majluf, 1984, "Corporate financing and investment decisions when firms have information that investors do not have," Journal of financial economics, Vol. 13, No. 2, pp. 187-221.

Poterba, James M., Robert E. Hall, and R. Glenn Hubbard, 1987, “Tax Policy and Corporate Saving," Brookings Papers on Economic Activity, Vol. 1987, No. 2, pp. pp. 455-515.

Ricciuti, Roberto, 2003, “Assessing Ricardian Equivalence,” Journal of Economic Surveys, Vol. 17, No. 1, pp. 55-78.

Seater, John J., 1993, "Ricardian Equivalence,” Journal of Economic Literature, Vol. 31, No. 1, pp. 142-90. 


\section{Appendix A. Proofs}

\section{A.1. Ricardian equivalence result with Corporate Taxation}

Let $\mathcal{Z}=\left\{\tau_{t}, B_{t+1}\right\}_{t=0}^{+\infty}$ and $\hat{\mathcal{Z}}=\left\{\hat{\tau}_{t}, \hat{B}_{t+1}\right\}_{t=0}^{+\infty}$ where:

$\sum_{t=0}^{+\infty} \prod_{i=0}^{t}\left(1+r_{i}\right)^{-1} \hat{\tau}_{t}=\sum_{t=0}^{+\infty} \prod_{i=0}^{t}\left(1+r_{i}\right)^{-1} \tau_{t}, X$ denote the equilibrium value of the variable $X$ under $\mathcal{Z}$, and $\hat{X}$ the value under $\hat{\mathcal{Z}}$. If $\Xi \equiv\left\{C_{t}, N_{t}, K_{t+1}, \theta_{t+1}\right\}$, then the equilibrium allocations under the policy $\mathcal{Z}$ is $\left\{\Xi_{t}, B_{t+1}^{h}, d_{t}\right\}_{t=0}^{+\infty}$ where $B_{t+1}^{h}$ represents the household's investment in government bonds. Given the initial conditions, the proof proceeds in two steps. First, it shows that the changes in the timing of the tax policy do not affect the value of the firm, i.e., $V_{0}=\hat{V}_{0}$. Second, it proves that $\left\{\Xi_{t}, \hat{B}_{t+1}^{h}, \hat{d}_{t}\right\}_{t=0}^{+\infty}$ is the competitive equilibrium allocations under the policy $\hat{\mathcal{Z}}$ under the initial price system.

$$
\begin{gathered}
V_{0}=\max _{\left\{K_{t+1}, N_{t}\right\}_{t=0}^{+\infty}} \sum_{t=0}^{+\infty} \Lambda_{0, t}\left[F\left(K_{t}, N_{t}\right)+(1-\delta) K_{t}-w_{t} N_{t}-K_{t+1}-\tau_{t}\right] \\
V_{0}=-\sum_{t=0}^{+\infty} \Lambda_{0, t} \tau_{t}+\max _{\left\{K_{t+1}, N_{t}\right\}_{t=0}^{+\infty}} \mathrm{H}\left(K_{t+1}, N_{t}\right) \\
\hat{V}_{0}=-\sum_{t=0}^{+\infty} \Lambda_{0, t} \hat{\tau}_{t}+\max _{\left\{K_{t+1}, N_{t}\right\}_{t=0}^{+\infty}} \mathrm{H}\left(K_{t+1}, N_{t}\right)=-\sum_{t=0}^{+\infty} \Lambda_{0, t} \tau_{t}+\max _{\left\{K_{t+1}, N_{t}\right\}_{t=0}^{+\infty}} \mathrm{H}\left(K_{t+1}, N_{t}\right) .
\end{gathered}
$$

In addition, $\left\{K_{t+1}, N_{t}\right\}_{t=0}^{+\infty}=\operatorname{argmax} \mathrm{H}\left(K_{t+1}, N_{t}\right)=\operatorname{argmax} V_{0}=\operatorname{argmax} \hat{V}_{0}$. Thus, $\left\{K_{t+1}, N_{t}\right\}_{t=0}^{+\infty}$ is the equilibrium investment and employment allocations under $\hat{\mathcal{Z}}$, i.e. $\left\{K_{t+1}, N_{t}\right\}_{t=0}^{+\infty}=$ $\left\{\hat{K}_{t+1}, \hat{N}_{t}\right\}_{t=0}^{+\infty}$. Since the change in the tax path does not affect the household's optimality conditions, proving that $\left\{C_{t}, \theta_{t+1}, B_{t+1}^{h}\right\}_{t=0}^{+\infty}$ remains the equilibrium allocations under $\hat{\mathcal{Z}}$ amounts to showing that these allocations are feasible under the household's budget constraint and consistent with market clearing conditions.

From the good's market clearing conditions: $\forall t, C_{t}=F\left(K_{t}, N_{t}\right)+(1-\delta) K_{t}-K_{t+1}-G_{t}=$ $F\left(\hat{K}_{t}, \hat{N}_{t}\right)+(1-\delta) \hat{K}_{t}-\hat{K}_{t+1}-G_{t} \cdot\left\{C_{t}\right\}_{t=0}^{+\infty}$ is feasible. Next, I choose $\forall t, \theta_{t}=1$ consistent with firm's shares market clearing, and shows that the implied household's investment in government bonds is consistent with the bond's market clearing condition. The household budget constraint implies: $\hat{B}_{t+1}^{h}-R_{t} \hat{B}_{t}^{h}=\hat{d}_{t}+w_{t} N_{t}-C_{t}$. Thus, these allocations are feasible under $\hat{\mathcal{Z}}$ by construction. Next, I show that they are consistent with the bond's market clearing condition. Using the resource constraint of the firm: $\hat{d}_{t}=F\left(K_{t}, N_{t}\right)+(1-\delta) K_{t}-w_{t} N_{t}-$ $K_{t+1}-\hat{\tau}_{t}$, implying $\hat{B}_{t+1}^{h}-R_{t} \hat{B}_{t}^{h}=F\left(K_{t}, N_{t}\right)+(1-\delta) K_{t}-K_{t+1}-\hat{\tau}_{t}-C_{t}$. From the good's 
market clearing condition: $F\left(K_{t}, N_{t}\right)+(1-\delta) K_{t}-K_{t+1}-C_{t}=G$. Thus, $\hat{B}_{t+1}^{h}-R_{t} \hat{B}_{t}^{h}=$ $G-\hat{\tau}_{t}=\hat{B}_{t+1}-R_{t} \hat{B}_{t}$. Starting from the initial condition $\hat{B}_{0}^{h}=\hat{B}_{0}$ and solving forward implies $\hat{B}_{t+1}^{h}=\hat{B}_{t+1}, \forall t$. Next, I prove that this new debt path satisfies the transversality condition.

$$
\begin{aligned}
& \hat{B}_{T+1}=R_{T} \hat{B}_{T}+G-\hat{\tau}_{T} \Rightarrow \lim _{T \rightarrow \infty} \prod_{t=0}^{T} R_{t}^{-1} \hat{B}_{t+1}=\lim _{T \rightarrow \infty}-\sum_{t=0}^{T} \prod_{i=0}^{t} R_{i}^{-1}\left(\hat{\tau}_{t}-G_{t}\right)+B_{0}=\lim _{T \rightarrow \infty}-\sum_{t=0}^{T} \prod_{i=0}^{t} R_{i}^{-1}\left(\tau_{t}-\right. \\
& \left.G_{t}\right)-B_{0} \equiv 0 .
\end{aligned}
$$

\section{A.2. Proof of lemma 1}

Under lump sum tax, the consumption at steady-state is given by:

$$
\begin{array}{cc}
C_{s s}=\left(\frac{\alpha \beta}{1-\beta(1-\delta)}\right)^{\frac{\alpha}{1-\alpha}}\left[1-\alpha+\frac{\alpha(1-\beta)}{(1-\beta(1-\delta))\left(1-\kappa \mathbf{1}_{\left.D_{s s}<\hat{D}\right)}\right.}\right] & -\frac{(\bar{\tau}+\hat{D}) \kappa \mathbf{1}_{D_{s s}<\hat{D}}}{1-\kappa \mathbf{1}_{D_{s s}<\hat{D}}}-G l \\
C_{s s}=0 \Rightarrow G=\left(\frac{\alpha \beta}{1-\beta(1-\delta)}\right)^{\frac{\alpha}{1-\alpha}}\left[(1-\alpha)(1-\kappa)+\frac{\alpha(1-\beta)}{(1-\beta(1-\delta))}\right]-\hat{D} \kappa \equiv \hat{G}_{l} .
\end{array}
$$

\section{A.3. Proof of proposition 4}

Under lump-sum tax:

$$
\begin{gathered}
D_{s s}-\hat{D}=\frac{1}{1-\kappa \mathbf{1}_{D_{s s}<\hat{D}}}\left[\frac{(1-\beta)}{\beta}\left(\frac{\alpha \beta}{1-\beta(1-\delta)}\right)^{\frac{1}{1-\alpha}}-G_{l}-\hat{D} \kappa \mathbf{1}_{D_{s s}<\hat{D}}\right] \\
D_{s s}-\hat{D}=\frac{1}{1-\kappa 1_{D_{s s}<\hat{D}}}\left(\hat{D}_{h i}^{l}-\hat{D}-G_{l}\right) . \\
\hat{D}<\hat{D}_{h i}^{l} \Rightarrow\left(D_{s s}-\hat{D}<-G_{l}<0\right) .
\end{gathered}
$$

\section{A.4. Proof of Proposition 5}

Under lump-sum tax:

$$
\begin{gathered}
D_{s s}=\frac{1}{1-\kappa \mathbf{1}_{D_{s s}<\hat{D}}}\left[\frac{\alpha(1-\beta)}{1-\beta(1-\delta)}\left(\frac{\alpha \beta}{1-\beta(1-\delta)}\right)^{\frac{\alpha}{1-\alpha}}-G_{l}-\hat{D} \kappa \mathbf{1}_{D_{s s}<\hat{D}}\right] \\
D_{s s}<\hat{D} \Leftrightarrow G_{l}>\frac{1-\beta}{\beta}\left(\frac{\alpha \beta}{1-\beta(1-\delta)}\right)^{\frac{1}{1-\alpha}}-\hat{D} \equiv \bar{G}_{l} .
\end{gathered}
$$




\section{A.5. Proof of Proposition 6}

$$
\begin{gathered}
\hat{G}_{l}-\bar{G}_{l}=\left(\frac{\alpha \beta}{1-\beta(1-\delta)}\right)^{\frac{\alpha}{1-\alpha}}\left[(1-\alpha)(1-\kappa)+\frac{\alpha(1-\beta)}{(1-\beta(1-\delta))}\right]- \\
\hat{D} \kappa-\frac{\alpha(1-\beta)}{1-\beta(1-\delta)}\left(\frac{\alpha \beta}{1-\beta(1-\delta)}\right)^{\frac{\alpha}{1-\alpha}}+\hat{D} \\
\hat{G}_{l}-\bar{G}_{l}>0 \Longleftrightarrow \hat{D}>-(1-\alpha)\left(\frac{\alpha \beta}{1-\beta(1-\delta)}\right)^{\frac{\alpha}{1-\alpha}} \equiv \hat{D}_{l o}^{l} .
\end{gathered}
$$

\section{A.6. Proof of Lemma 2}

Under proportional tax, the steady state government debt is:

$$
\begin{aligned}
& B_{s s}=\frac{\beta}{1-\beta}\left[\left(\frac{\alpha \beta(1-\bar{\tau})}{1-\beta+\delta \beta(1-\bar{\tau})}\right)^{\frac{\alpha}{1-\alpha}} \frac{\alpha(1-\beta) \bar{\tau}}{1-\beta+\delta \beta(1-\bar{\tau})}-G\right] \\
& B_{s s}=0 \Leftrightarrow G(\tau)=\left(\frac{\alpha \beta(1-\tau)}{1-\beta+\delta \beta(1-\tau)}\right)^{\frac{\alpha}{1-\alpha}} \frac{\alpha(1-\beta) \tau}{1-\beta+\delta \beta(1-\tau)} \\
& {[G(\tau)=\exp [\ln G(\tau)]] \Longleftrightarrow\left[\frac{\partial G(\tau)}{\partial \tau}=\frac{\partial \ln G(\tau)}{\partial \tau} \exp [\ln G(\tau)]\right]} \\
& \Longleftrightarrow\left[\frac{\partial G(\tau)}{\partial \tau}>0 \Longleftrightarrow \frac{\partial \ln G(\tau)}{\partial \tau}>0\right] \\
& {\left[\frac{\partial \ln G}{\partial \tau}=\frac{(1-\tau)(1-\beta+\delta \beta-\alpha \delta \beta)-\alpha(1-\beta)}{\tau(1-\alpha)(1-\tau)[1-\beta+\delta \beta(1-\tau)]}\right] \Longleftrightarrow} \\
& {\left[\frac{\partial \ln G(\tau)}{\partial \tau}>0 \Leftrightarrow \tau<\frac{(1-\beta+\delta \beta)(1-\alpha)}{1-\beta+\delta \beta(1-\alpha)} \equiv \hat{\tau}_{p}\right]} \\
& G\left(\hat{\tau}_{p}\right)=\hat{G}_{p}=\left[\frac{\alpha \beta \frac{(1-\beta) \alpha}{1-\beta+\delta \beta(1-\alpha)}}{1-\beta+\delta \beta\left(\frac{(1-\beta) \alpha}{1-\beta+\delta \beta(1-\alpha)}\right)}\right]^{\frac{\alpha}{1-\alpha}}\left[\frac{\alpha(1-\beta) \frac{(1-\beta+\delta \beta)(1-\alpha)}{1-\beta+\delta(1-\alpha)}}{1-\beta+\delta \beta\left(\frac{(1-\beta) \alpha}{1-\beta+\delta \beta(1-\alpha)}\right)}\right] \\
& \Longleftrightarrow \hat{G}_{p}=\alpha(1-\alpha)\left(\frac{\alpha^{2} \beta}{1-\beta+\delta \beta}\right)^{\frac{\alpha}{1-\alpha}} \\
& \left\{\left[\hat{\tau}_{p}=\frac{(1-\beta+\delta \beta)(1-\alpha)}{1-\beta+\delta \beta(1-\alpha)}>0\right] \text { and }\left[1-\hat{\tau}_{p}=\frac{(1-\beta) \alpha}{1-\beta+\delta \beta(1-\alpha)}>0\right]\right\} \text {. }
\end{aligned}
$$




\section{A.7. Proof of Proposition 7}

The proof is established as follow:

1.

$$
\begin{aligned}
\hat{D}_{l}^{l o}=(1-\alpha)\left(\frac{\alpha \beta}{1-\beta(1-\delta)}\right)^{\frac{\alpha}{1-\alpha}}<\hat{D}_{p}^{l o}= & \\
\qquad & \frac{1-\beta}{\beta}\left[\frac{\alpha^{2} \beta}{1-\beta+\alpha \delta \beta^{2}+\delta \beta(1-\beta)}\right]^{\frac{1}{1-\alpha}}
\end{aligned}
$$

2. $\hat{D}_{p}^{l o}=\frac{1-\beta}{\beta}\left[\frac{\alpha^{2} \beta}{1-\beta+\alpha \delta \beta^{2}+\delta \beta(1-\beta)}\right]^{\frac{1}{1-\alpha}}<\hat{D}_{p}^{h i}=\frac{1-\beta}{\beta}\left(\frac{\alpha}{\delta}\right)^{\frac{1}{1-\alpha}}$

3.

$$
\begin{aligned}
\hat{D}_{p}^{l o}=\frac{1-\beta}{\beta}\left[\frac{\alpha^{2} \beta}{1-\beta+\alpha \delta \beta^{2}+\delta \beta-\delta \beta^{2}}\right]^{\frac{1}{1-\alpha}}<\hat{D}_{l}^{h i}= & \\
& \frac{1-\beta}{\beta}\left[\frac{\alpha \beta}{1-\beta(1-\delta)}\right]^{\frac{1}{1-\alpha}}
\end{aligned}
$$

4. $\hat{D}_{l}^{h i}=\frac{1-\beta}{\beta}\left[\frac{\alpha \beta}{1-\beta(1-\delta)}\right]^{\frac{1}{1-\alpha}}<\hat{D}_{p}^{h i}=\frac{1-\beta}{\beta}\left(\frac{\alpha}{\delta}\right)^{\frac{1}{1-\alpha}}$.

\section{A.8. Proof of Proposition 8}

Assume that $\hat{D}<\hat{D}_{l}^{h i}$. Proposition 7 implies that $\hat{D}<\hat{D}_{p}^{h i}$. Given this result, I first prove that:

$$
D_{s s}<\hat{D} \Longleftrightarrow \tau>\frac{\alpha \beta^{\alpha}(1-\beta)^{1-\alpha}-\hat{D}^{1-\alpha}(1-\beta+\delta \beta)}{\alpha \beta^{\alpha}(1-\beta)^{1-\alpha}-\delta \beta \hat{D}^{1-\alpha}} \equiv \bar{\tau}_{p}
$$

Thereafter, I derive the expression of the corresponding government spending:

$$
G\left(\bar{\tau}_{p}\right)=\alpha\left(\frac{\beta \hat{D}}{1-\beta}\right)^{\alpha}+\delta \frac{\beta \hat{D}}{1-\beta}-\hat{D} \equiv \bar{G}_{p}
$$

Finally, I show that: $\hat{D}<\hat{D}_{l}^{h i} \Longrightarrow \bar{\tau}_{p}>0$ 


\section{A.9. Proof of lemma 3}

Lemma 2 and proposition 8 have shown $\hat{\tau}_{p}<1$ and $\bar{\tau}_{p}>0$, respectively. Then, the proof consists in:

$$
\hat{D}_{p}^{l o}=\frac{1-\beta}{\beta}\left[\frac{\alpha^{2} \beta}{1-\beta+\alpha \delta \beta^{2}+\delta \beta-\delta \beta^{2}}\right]^{\frac{1}{1-\alpha}}<\hat{D}<\hat{D}_{p}^{h i}=\frac{1-\beta}{\beta}\left(\frac{\alpha}{\delta}\right)^{\frac{1}{1-\alpha}}
$$

$$
\Longleftrightarrow \bar{\tau}_{p}<\hat{\tau}_{p}
$$

First, I define $\overline{\bar{\tau}}_{p}=\frac{(1-\alpha)(1+\delta \beta)}{1+\delta \beta(1-\alpha)}$. Afterwards, I show that:

$\bar{\tau}_{p}<\overline{\bar{\tau}}_{p} \Longleftrightarrow \frac{1-\beta}{\beta}\left(\frac{\alpha}{\delta}\right)^{\frac{1}{1-\alpha}}>\hat{D}>\frac{1-\beta}{\beta}\left[\frac{\alpha^{2} \beta}{1-\beta+\alpha \delta \beta^{2}+\delta \beta(1-\beta)}\right]^{\frac{1}{1-\alpha}}$.

Then, I prove $\overline{\bar{\tau}}_{p}<\hat{\tau}_{p}$.

\section{Appendix B. Numerical Algorithm}

The algorithm used to compute the transition dynamics of the economy when tax is lump sum is as follows:

1. Solve for the steady state and fix a length for the transition.

2. Make a guess on the status of the constraint for each period of the transition.

3. Given the initial stock of capital and the tax rate after tax cut, make a guess for initial consumption.

4. Given the guess for consumption, use the household's resource constraint to derive the dividend.

5. Given conjecture on the status of the constraint, use the firm's resource constraint to derive the investment.

6. Given the capital choice of next period and the status of the constraint, use the firm's Euler equation to determine the interest rate.

7. Given the interest rate, use the household's Euler equation to have a guess of the future consumption and tax rate.

8. Given the interest rate, the tax cuts and the zero debt government condition for the next period, use the government budget constraint to update the conjecture of the future tax 
rate. This step is necessarily only for the period after the tax cut. For the other periods, the tax rate is the same as in steady state.

9. Repeat steps 3 to 8 until convergence of the investment decision to its steady state value. If the investment decision does not converge before the end of the transition, go back to step 3 and update the guess on consumption.

10. After convergence, use the path of dividend and investment to check the conjecture of the status of the constraint. If the conjecture is correct then stop. Otherwise, go back to step 3 and update the conjecture on the status of the constraint. 